\title{
Article \\ A Disproportionality Bias in the Bureau of the Regional Assembly of Madrid
}

\author{
Omar de la Cruz Vicente ${ }^{1, *(\mathbb{D})}$, Fernando Tomé Bermejo ${ }^{1}\left[\right.$ and Rafael Ramiro Moreno ${ }^{2}(\mathbb{D}$ \\ 1 Departamento de Economía y Empresa, Facultad de Ciencias Sociales, Universidad Nebrija, \\ 28240 Madrid, Spain; ftome@nebrija.es \\ 2 ICADE Business School, Facultad de Ciencias Económicas y Empresariales, Universidad Pontificia Comillas, \\ 28015 Madrid, Spain; rramiro@comillas.edu \\ * Correspondence: ocruz@nebrija.es
}

check for updates

Citation: de la Cruz Vicente, O.; Tomé Bermejo, F.; Ramiro Moreno, R. A Disproportionality Bias in the Bureau of the Regional Assembly of Madrid. Games 2021, 12, 92. https:// doi.org/10.3390/g12040092

Academic Editors: Ulrich Berger and Maria Montero

Received: 27 September 2021

Accepted: 3 December 2021

Published: 7 December 2021

Publisher's Note: MDPI stays neutral with regard to jurisdictional claims in published maps and institutional affiliations.

Copyright: (c) 2021 by the authors. Licensee MDPI, Basel, Switzerland. This article is an open access article distributed under the terms and conditions of the Creative Commons Attribution (CC BY) license (https:// creativecommons.org/licenses/by/ $4.0 /)$.

\begin{abstract}
This paper analyses the voting behavior of the parliamentary groups in the Regional Assembly of Madrid to appoint the Bureau, its representative body, in all the legislatures since its inception (1983-2021). To this end, the actual result of the voting is compared with the mock result attained by following a Nash equilibrium (NE) and a d'Hondt $\left(\mathrm{d}^{\prime} \mathrm{H}\right)$ allocation in each vote. But the result of a d'Hondt allocation varies based on the number of stages in which the voting is performed (President, Vice-President, and Secretaries), so a bias towards disproportionality could exist as measured by the absolute index of disproportionality which calculates the number of seats non-proportionally allocated. The results show that, in view of the hypothesis on the importance of the number of seats, the NE was only followed in four of the 12 Legislatures for Vice-Presidents (it was always followed for Secretaries). Thus, parliamentary groups could gain more seats by modifying their strategies. Additionally, the absolute rate of disproportionality and the number of seats non-proportionally allocated indicate that, in general, parliamentary groups obtain voting results that are less disproportionate than they could be (due to the number of voting stages).
\end{abstract}

Keywords: Nash equilibrium; d'Hondt rule; parliament; disproportionality bias

\section{Introduction}

In the Regional Parliament of the Community of Madrid, at the beginning of each legislature, there is a key parliamentary voting situation in which the members of the Assembly elect their representative body: the Bureau.

According to articles 48 and 49 of the Rules of Procedure, the Bureau of the Assembly of Madrid is a governing body that holds representative functions, organizes the workload, and sets internal rules and procedures. The Bureau is constituted by a President, three VicePresidents and three Secretaries. The voting procedure is the same as in the National Congress of Deputies (one President, four Vice-Presidents and four Secretaries), but adapted to the number of seats. Similar methods are also used in other regional parliaments in Spain.

According to article 52 of the Rules of Procedure of the Assembly of Madrid [1]:

\section{Article 52}

1. Elections for the Presidency, Vice-Presidencies and Secretariats shall be held successively and by secret ballot.

2. In the election of the Presidency, each Member shall write one name only, on the appropriate ballot paper. The Member who obtains the vote of an absolute majority of the Members of the Assembly shall be elected. If no Member obtains such an absolute majority in the first ballot, the election shall be repeated between the two Members who obtained the highest number of votes in the previous ballot, and the Member who obtains the highest number of votes in the new ballot shall be elected. 
3. The three Vice-Presidencies shall be elected simultaneously. Each Member shall write one name only, on the appropriate ballot paper. The three Members that obtain the highest number of votes, shall be elected in successive order.

4. The three Secretariats shall be elected in two successive ballots.

In the first ballot, the First Secretariat and the Second Secretariat shall be elected. Each Member shall write one name only, on the corresponding ballot paper. The two Members that obtain the highest number of votes shall be elected in successive order.

In the second ballot, the Third Secretary shall be elected. Each Member shall write only one name on the ballot paper. The Member that obtains the highest number of votes shall be elected.

5. Should there be a tie in any of the votes referred to in the preceding paragraphs, successive ballots shall be held among the Members with the same number of votes until the tie is broken. However, if the tie persists in the fourth ballot, the Member who belongs to the same political party as the candidate with the highest number of votes in the regional elections shall be deemed to be elected.

6. Under no circumstances can there be more than four Members elected from the same party.

The motivation of the paper is the analysis of the consequences of voting by stages in proportional representation of the parliament bureau. In particular, the Assembly of Madrid is unique because Secretaries are voted in two separated stages, while in other regional parliaments, all the Secretaries are voted in a single ballot. Moreover, we would like to study the number of members groups obtained in the Bureau by comparing the real vote (ex-post) with the model defined in [2].

It is worth looking at the differences in voting for all three members at the same time and voting for them separately. To do so, think of a parliament divided in two political groups $(102,50)$. The candidate with more votes wins. Then, by voting separately for two posts and later for one, the group with more seats could divide 102 seats into 51 votes for each candidate (against 50 votes of the minority group) in the vote for two posts (wining both) and it will also obtain the third member (102 vs. 50). Therefore, the majority group with 102 seats gets three posts; whereas, if all three seats were voted for at once, it would only get two seats, because it will divide it into two $(51,51)$ and the group with 50 seats will cluster all of them in one candidate. Therefore, $(51,51,50)$ will be the votes and the result will be $(2,1)$.

That problematic situation hints at a possible lack of proportionality caused by holding an additional vote to name the last Secretary. In this regard, this paper broadens the scope of analysis with several options: voting for all the posts in a single ballot or stage; a twostage ballot for the President and then for the remaining six seats; a three-stage ballot for the President, the three Vice-Presidents and the three Secretaries; and finally, the actual voting, which is the vote for the President, the three Vice-Presidents, two Secretaries and the third Secretary in four stages.

Think of the voting for the Vice-presidents or Secretaries of the Bureau as a static game, in which the players are the parliamentary groups (with a certain number of Deputies), after alliances of individual parties were made. For each player, a set of possible actions or strategies (how to redistribute the votes of their Deputies among the different candidates) must be defined to serve as the decisions to be taken. Then, a strategy profile is created by considering a strategy for each player. The game will end with payoffs for each player: the number of seats won.

Our approach assumes that positions are interchangeable, so the order of the sequence is not relevant, but the total number of positions attained is. In addition, based on [2] summarized in the theory section, the Nash equilibrium of each vote results in a d'Hondt allocation of the seats.

The main objective of this paper is to study the performance from the perspective of game theory and, in this real context, of the strategic decisions taken by each group. This applied research work has three main objectives: 
1. To calculate the Nash equilibrium and the relation with the d'Hondt distribution of the votes in the Assembly of Madrid in all the legislatures. Therefore, predictions of the number of seats by parliamentary groups will be compared with the data of all the legislatures.

2. To compare the number of seats obtained by each player (whether parliament group or coalition) applying the d'Hondt rule, with the ones that would be obtained by changing the number of stages used for the voting of all seats in all the legislatures of the Assembly of Madrid.

3. To obtain the differences in the absolute disproportionality index (and the number of seats non-proportionally allocated) determined by the number of stages in the voting of a Bureau. Also, to obtain the excess per player, when compared with a direct proportional distribution, for all the legislatures of the Assembly of Madrid.

Let us highlight two features that distinguish this contribution from the usual works in this field. The first refers to its nature as an empirical study on the Regional Parliament. There are many studies on the National House of Representatives and the Senate, regarding general elections [3-6]. Our study has the same approach but is applied to the Regional Assembly of Madrid voting for the Bureau. Second, and more importantly, we provide a measure of disproportionality as a function of voting stages. We compare these results with those calculated using the d'Hondt allocation and the Nash equilibrium following [2].

This article is structured as follows: first, the game is formalized, and basic concepts are defined. Second, literature is summarized and the methodology is outlined. Then, the results are stated and analysed. Finally, the conclusions are stated. All data and calculations are displayed in Appendix A.

\section{Game Formalized}

Let us consider a parliament with $n$ Deputies divided in $k$ parliamentary groups, $G_{1}$, $G_{2}, \ldots, G_{k}$. Each parliamentary group $G_{j}$ has $n_{j}$ Deputies $\sum_{j=1}^{k} n_{j}=n$. A committee with q interchangeable posts $(q \leq n)$ is going to be elected as a static game. Each group has some candidates.

- $\quad$ The players are the $k$ parliamentary groups $G_{1}, G_{2}, \ldots, G_{k}$.

- The actions or strategies of each group $G_{j}$, are expressible as n-vectors $a_{j}=\left(a_{j 1}, a_{j 2}\right.$, $\left.\ldots, a_{j n}\right)$ where $\mathrm{a}_{j i}$ means the global score awarded by the group $G_{j}$ to the $i t h$ potential candidate.

- Given any strategic profile $a=\left(a_{1}, \ldots, a_{k}\right)$, this determines the total scores obtained by every candidate, the sum of scores obtained by every group and the number of seats or positions obtained by every group.

- Their payoffs are the number of seats in the Bureau based on their strategies for allocating the seats between Deputies and candidates. The more seats in the bureau, the better the strategy of the group.

- $\quad$ The $q$ candidates with more votes are elected.

In Section 4, hypotheses of the game are explained to relate Nash Equilibrium and $d^{\prime}$ Hondt allocation. Therefore, in Section 3, basics concepts of the paper are defined, and examples are explained.

\section{Basic Concepts}

This section defines the Nash equilibrium applied to voting, the $\mathrm{d}^{\prime}$ Hondt allocation procedure and the absolute disproportionality index.

\subsection{The Nash Equilibrium}

In this regard, a well-known equilibrium analysis in game theory is the Nash equilibrium (NE), which refers to any profile of strategies that is optimal for each player, given the strategies of the other players. Thus, no player would wish to unilaterally change the decision taken. Formally speaking [7] defined that "in the game $G=\left\{S_{1}, \ldots, S_{n} ; u_{1}, \ldots, u_{n}\right\}$, where $S_{i}$ 
is the set of pure strategies (actions) of player $i$, and $u_{i}$ is the payoff function of that player, the profile of pure strategies $\left(s^{*}, s^{*}, \ldots, s^{*}{ }_{i}, \ldots, s_{n}^{*}\right)$ is a Nash equilibrium if, for each player $i, u_{i}\left(s^{*}{ }_{1}, s^{*}, \ldots, s^{*}{ }_{i}, \ldots, s^{*}\right) \geq u_{i}\left(s^{*}{ }_{1}, s^{*}{ }_{2}, \ldots, s_{i}, \ldots, s^{*}\right)$ for all $s_{i}$ of $s_{i}$. That is, for each player $i, s^{*}$ is a solution to the problem $\max u_{i}\left(s^{*}{ }_{1}, s^{*}, \ldots, s^{*}{ }_{i}, \ldots, s^{*}{ }_{n}\right)$ where $s_{i}$ is the decision variable and belongs to $S_{i}$. Or, in other words, for the player $i, s_{i}{ }_{i}$ is an optimal response to $s_{-i}^{*}=\left(s^{*}, s_{2}^{*}, \ldots, s^{*}{ }_{i-1}, s^{*}{ }_{i+1}, \ldots, s_{n}\right)^{\prime \prime}$.

To explain basic concepts like NE, a real voting election is considered. In the Regional Elections of the Assembly of Madrid of 2011 (IX Legislature) the seats obtained by each candidacy were in Tables 1-3. We have included a table in Appendix B with acronyms of each parliamentary group:

Table 1. Apportionment of seats in the IX Legislature.

\begin{tabular}{cccccc}
\hline Group & PP & PSOE & IU & UPyD & Total \\
\hline Number of seats & 72 & 36 & 13 & 8 & 129 \\
\hline
\end{tabular}

Table 2. Voting of Vice Presidents in the IX Legislature.

\begin{tabular}{cccccc}
\hline Group & PP & PSOE & IU & UPyD & Total \\
\hline Number of votes & 66 & 36 & $27=6+13+8$ & 129 \\
Vice Presidents (VP) & $1^{\circ} \mathrm{VP}$ & $2^{\circ} \mathrm{VP}$ & $3^{\circ} \mathrm{VP}$ & \\
\hline
\end{tabular}

Table 3. Voting of Secretaries in the IX Legislature.

\begin{tabular}{cccccc}
\hline Group & PP & PSOE & IU & UPyD & Sum \\
\hline Number of votes & 56 & 36 & & 37 & 129 \\
Secretaries (2) & $1^{\circ}$ Secret & & & $2^{\text {o Secret }}$ & \\
$\begin{array}{c}\text { Number of votes } \\
\text { Secretaries (1) }\end{array}$ & 72 & 36 & 13 & 8 & 129 \\
\hline
\end{tabular}

In the ballot to elect the three Vice-Presidents, the votes received by each candidate were:

The First Vice-President of the PP obtained only 66 of the 72 votes that the PP group had because a coalition was formed between PP, IU and UPyD to secure the third VicePresident. Following the assumptions of this paper regarding the importance of the number of seats, this result is a NE because, given the strategy of each coalition, the others has no incentive to modify the distribution to reach an additional position (the PP, IU and UPyD could not gain 3 positions, and PSOE could not gain two seats).

In the two separate ballots for the election of Secretaries, the votes were distributed as follows:

In the first ballot, two Secretaries were elected: the first one was for PP (with 56 votes), and the second one for UPyD with 37 votes (16 PP + 13 IU + 8 UPyD). PP got the third Secretary with 72 votes (the rest were blank). In this vote, the remark pointed out in the election of Vice-Presidents is corrected so that the voting of the three Secretaries separately is a NE, given the alliance of PP, IU and UPyD.

With a total of 129 seats (the number of seats in the Assembly of Madrid in the IX Legislature), if a group has more than 86 seats, it obtains all 3 positions by voting separately. Whereas, if all 3 positions were voted for all at once, it would need to have more than 97 seats. If two groups $(98,31)$ vote for 3 positions at once, the group with 98 will be divided in 33,33 , and 32 . In other words, voting separately gives the majority group more representation in relative terms than if the positions were voted all at once.

\subsection{D'Hondt Distribution and Other Proportional Rules}

There are two categories of elective formula: majority formulas and distributive or proportional formulas. The former, allocate the seat or seats to the candidate with the highest number of votes. On the other hand, distributive or proportional rules respond 
to the criterion that the provision of seats should be allocated according to the number of votes gained by each candidate and on a pro rata basis, instead of assigning them directly to the one who obtains the largest number of votes [7-10].

Among the many existing distributive formulas, the two most widespread are the formula of the largest remainder (or Hamilton rule) and the formula of the largest mean. Hamilton rule starts by calculating the quota, i.e., the number of total votes divided by the number of seats to allocate. Then, it distributes the seats by dividing the votes of each group by the quota and, if there are any unassigned seats, they are awarded to those groups with the largest remainders.

Jefferson rule, also known as d'Hondt after the Belgian professor who proposed it, is one of the variants of the second formula. The principle on which this formula is based, is that the average cost in votes to be paid to win a seat, should be substantially the same for each group. Thus, each seat is successively allocated to the group with the highest average number of votes per seat.

To formulate the concept, we call situation, the pair $(A, w)$ where, $\mathrm{A}$ is a k-vector of strictly positive integers $\left(m_{1}, m_{2}, \ldots, m_{k}\right)$ where $m_{i}$ is the contribution of agent $i$, i.e., the number of votes obtained by a political party $i$ or the population of a state $i$, and $w$ is the (integer) number of seats to be distributed among the agents (parties or states). It is assumed that $0<w \leq \sum_{i=1}^{k} m_{i}$. The allocation rule generates, for each situation $(A, w)$, a set of k-vectors known as allocation vectors, each one formed by the number of seats allocated to each agent.

Therefore, it is necessary to calculate the number of votes (integer or fractional) $d$, known as the divisor, which entitles it to a seat and then, the number of seats allocated to each group. The number $d$ is defined by requiring that $\sum_{i=1}^{k} I N T\left(\frac{m_{i}}{d}\right)=w$.

Given any situation $(A, w)$, the Jefferson-d'Hondt rule of $(A, w)$ leading to the collection of assignments $J-d H(A, w)$ is:

Case (a): if there is a divisor $d$, such that $\sum_{i=1}^{k} \operatorname{INT}\left(\frac{m_{i}}{d}\right)=w$ :

$$
J-d H(A, w)=\left\{\left(h_{1}, h_{2}, \ldots, h_{k}\right) \mid h_{i}=\operatorname{INT}\left(\frac{m_{i}}{d}\right)\right\}
$$

Case (b): if there is no divisor, let d' (denominated pseudo divisor) be the maximum real number such that $\sum_{i=1}^{k} I N T\left(\frac{m_{i}}{d^{\prime}}\right)>w$. Then:

$$
J-d H(A, w)=\left\{\begin{array}{l}
\left(h^{\prime}{ }_{1}, h^{\prime}{ }_{2}, \ldots, h^{\prime}{ }_{k}\right) \mid \sum_{i=1}^{k} h_{i}^{\prime}=w, \\
h^{\prime}=\operatorname{INT}\left(\frac{m_{j}}{d^{\prime}}\right) \text { if } \frac{m_{j}}{d^{\prime}}>\operatorname{INT}\left(\frac{m_{j}}{d^{\prime}}\right) \\
\operatorname{INT}\left(\frac{m_{j}}{d^{\prime}}\right)-1 \leq h^{\prime} \leq \operatorname{INT}\left(\frac{m_{j}}{d^{\prime}}\right) \text { if } \frac{m_{j}}{d^{\prime}}=\operatorname{INT}\left(\frac{m_{j}}{d^{\prime}}\right)
\end{array}\right\}
$$

Situations $(A, w)$ for which case (a) applies, so that there are no ties and the rule $J-d H(A, w)$ is unitary, are called splitter situations. For these situations, the set of divisors $D=\left\{d \mid \sum_{i=1}^{k} \operatorname{INT}\left(\frac{m_{i}}{d}\right)=w\right\}$ is always a semi-open interval $\left[d_{i n f}, d_{\max }\right]$ denominated the range of dividers.

To illustrate an extended example of d'Hondt Rule is explained:

(a) Think about a situation made of five groups with 42, 28, 10, 10 and 10 Members respectively. The Assembly must elect a six-seat committee.

Briefly, the situation $(A, q)$ would be $\left(m_{1}, m_{2}, m_{3}, m_{4}, m_{5}\right)=(42,28,10,10,10)$, with $q=6$. This is a splitter situation. A divisor is, for example, $d=10.5$, because $h_{1}=\operatorname{INT}\left(\frac{m_{1}}{d}\right)$ $=\operatorname{INT}\left(\frac{42}{10.5}\right)=4, h_{2}=\operatorname{INT}\left(\frac{m_{2}}{d}\right)=\operatorname{INT}\left(\frac{28}{10.5}\right)=2, h_{3}=h_{4}=h_{5}=\operatorname{INT}\left(\frac{m_{3}}{d}\right)=\operatorname{INT}\left(\frac{10}{10.5}\right)=0$, complying with $\sum_{i=1}^{5} \operatorname{INT}\left(\frac{m_{i}}{d}\right)=6$. In this case $d_{i n f}=10$ and $d_{\max }=10.5$, and the allocation with the $\mathrm{d}^{\prime}$ Hondt rule is $J-d H(A, q)=\{(4,2,0,0,0)\}$.

There is another, simpler way of calculating that situation which is often used: by dividing the number of votes for each group by $1,2,3$, 4, etc., up to the total number of 
seats to be assigned. Then, the resulting ratios are ordered from highest to lowest. Finally, the candidates are drawn from the groups with the highest ratios.

Then, the D'Hondt rule allocation table with 100 voters distributed in five groups, with votes obtained or sizes $42,28,10,10,10$, and with six seats to be allocated (in bold are the ratios that are allocated a seat) displays in Table 4:

Table 4. D'Hondt rule allocation table-example with five groups and 100 votes.

\begin{tabular}{|c|c|c|c|c|c|c|c|c|}
\hline & $\mathbf{N}^{\circ}$ Votes $=100$ & $\mathrm{~N}^{0}$ Votes/1 & $\mathrm{N}^{0}$ Votes/2 & $N^{0}$ Votes $/ 3$ & $\mathrm{~N}^{\circ}$ Votes/4 & $\mathbf{N}^{\circ}$ Votes/5 & $\mathbf{N}^{\circ}$ Votes/6 & $\begin{array}{l}\text { Total } \\
q=6\end{array}$ \\
\hline $\mathrm{G}_{1}$ & 42 & 42 & 21 & 14 & 10.5 & 8.4 & 7 & 4 \\
\hline $\mathrm{G}_{2}$ & 28 & 28 & 14 & 9.33 & 7 & 5.6 & 4.66 & 2 \\
\hline $\mathrm{G}_{3}$ & 10 & 10 & 5 & 3.33 & 2.5 & 2 & 1.66 & 0 \\
\hline $\mathrm{G}_{4}$ & 10 & 10 & 5 & 3.33 & 2.5 & 2 & 1.66 & 0 \\
\hline $\mathrm{G}_{5}$ & 10 & 10 & 5 & 3.33 & 2.5 & 2 & 1.66 & 0 \\
\hline
\end{tabular}

(b) The same distribution of groups, but with 7 positions to fill, i.e., $(42,28,10,10,10)$ with $q=7$. In this case, there is no divisor $d$ such as $\sum_{i=1}^{5} \operatorname{INT}\left(\frac{m_{i}}{d}\right)=7$ and $d^{\prime}=10$ is the pseudo divisor (maximum number such as $\sum_{i=1}^{5} \operatorname{INT}\left(\frac{m_{i}}{d}\right)>7$ ). Since $\frac{m_{1}}{d^{\prime}}=\frac{42}{10}>\operatorname{INT}\left(\frac{m_{1}}{d^{\prime}}\right)=4$, $\frac{m_{2}}{d^{\prime}}=\frac{28}{10}>\operatorname{INT}\left(\frac{m_{2}}{d^{\prime}}\right)=2, \frac{m_{3}}{d^{\prime}}=\frac{m_{4}}{d^{\prime}}=\frac{m_{5}}{d^{\prime}}=\frac{10}{10}=\operatorname{INT}\left(\frac{m_{3}}{d^{\prime}}\right)=\operatorname{INT}\left(\frac{m_{4}}{d^{\prime}}\right)=\operatorname{INT}\left(\frac{m_{5}}{d^{\prime}}\right)=1$, it must be $J-d H(A, q)=\{(4,2,1,0,0),(4,2,0,1,0),(4,2,0,0,1)\}$. There is a three-way tie at 10 between groups 3,4 , and 5 for the last place.

An alternative formula to the major mean formula is the major remainder formula, which is also used in multi-member districts. To distribute seats, it is required to calculate the electoral quota or remainder, that allocates a seat. This quota is calculated by dividing the total number of votes by the number of seats to be filled.

The Hamilton rule is a variant of the largest remainder formula that allocates seats according to the division of the number of votes of each political group by the quota, i.e., according to the integers of these quotients. If, after this calculation, there were still seats to be allocated, the groups with larger remainders would receive an additional seat. Therefore, the remaining seats will be allocated to the political groups with the highest fraction of the quota, i.e., those with the largest remainders.

For example, a situation with 100 voters is divided into four groups with sizes 51, 32, 9 and 8 , and 4 seats to fill. The quota is $25(=100 / 4)$. The quotients of dividing the votes of each group by the quota are $2.04(=51 / 25), 1.28(=32 / 25), 0.36(=9 / 25)$ and $0.32(=8 / 25)$, respectively. The first allocation would be $2,1,0,0$, totaling three posts. As there is one place left to fill, it is assigned to the group with the largest remainder. It is the third one, whose fractional part 0.36 is the largest and, therefore, its remainder will be the largest. Hence, the final Hamilton rule allocation is 2, 1, 1 and 0 , respectively (Tables 5 and 6).

Table 5. Hamilton rule allocation table-example with four groups and 100 votes.

\begin{tabular}{cccccc}
\hline & $\mathbf{N}^{\mathbf{0}}$ Votes $=\mathbf{1 0 0}$ & $\mathbf{N}^{\mathbf{0}}$ Votes/Quota & Assigned Posts $=\mathbf{3}$ & Rests & Posts $=\mathbf{4}$ \\
\hline G1 & 51 & 2.04 & 2 & 0.04 & 2 \\
G2 & 32 & 1.28 & 1 & 0.28 & 1 \\
G3 & 9 & 0.36 & 0 & 0.36 & 1 \\
G4 & 8 & 0.32 & 0 & 0.32 & 0 \\
\hline
\end{tabular}

Table 6. D'Hondt rule allocation table-example with four groups and 100 votes.

\begin{tabular}{ccccccc}
\hline & $\mathbf{N}^{\mathbf{o}}$ Votes $\mathbf{= 1 0 0}$ & $\mathbf{N}^{\mathbf{o}}$ Votes/1 & $\mathbf{N}^{\mathbf{0}}$ Votes/2 & $\mathbf{N}^{\mathbf{0}}$ Votes/3 & $\mathbf{N}^{\mathbf{o}}$ Votes/4 & Posts $=\mathbf{4}$ \\
\hline G1 & 51 & 51 & 25.5 & 17 & 12.75 & 3 \\
G2 & 32 & 32 & 16 & 10.66 & 8 & 1 \\
G3 & 9 & 9 & 5 & 3.33 & 2.5 & 0 \\
G4 & 8 & 8 & 5 & 3.33 & 2.5 & 0 \\
\hline
\end{tabular}


This same example with the $\mathrm{d}^{\prime}$ Hondt rule would give a different result:

The first group is the majority group and is favored under the d'Hondt rule by gaining one more seat than the allocation of seats under the Hamilton rule.

Larger remainder distributive formulas (such as the Hamilton rule) are, in principle, the most favorable to a distribution of seats that most closely approximates the distribution of votes between candidates. By contrast, distributive formulas of the largest mean (such as the $d^{\prime}$ Hondt rule) generally favor the majority groups. However, the application of larger remainder formulas is normally administered with electoral constraints which prevent groups that do not exceed a certain number of votes from participating in the distribution of seats.

If we follow the Regional Election of the Assembly of Madrid of 2011, a different result is drawn because of the voting of three Secretaries in one stage or in two stages: two Secretaries were voted for first, and later, a third one was voted for separately. The distribution of the seats between PP, PSOE, IU, UpyD was $(72,36,13,8)$, respectively. The $\mathrm{d}^{\prime}$ Hondt allocation of voting in two stages was 3 Secretaries for Group PP + IU + UPyD and 0 for PSOE while, if the election had been done in one stage, it would have been $(2,1)$ for PP + IU + UPyD and PSOE, respectively, as shown in Table 7.

Table 7. Alliances and d'Hondt allocation in the IX Legislature.

\begin{tabular}{ccccc}
\hline Alliances & $\mathbf{N}^{\mathbf{o}}$ Votes & $\mathbf{N}^{\mathbf{o}}$ Votes $/ \mathbf{1}$ & $\mathbf{N}^{\mathbf{0}}$ Votes/2 & $\mathbf{N}^{\mathbf{0}}$ Votes/3 \\
\hline PP + IU + UPyD & 93 & 93 & 46.5 & 31 \\
PSOE & 36 & 36 & 18 & 12 \\
\hline
\end{tabular}

If the voting of the three Secretaries had been simultaneous (as happened in the vote for Vice-Presidents or in other parliaments), then PSOE would have been guaranteed $1 \mathrm{Sec}-$ retary. If the 93 votes of PP, IU and UPyD had been divided by three, each candidate would have been granted 31 votes. That way, PSOE would have been guaranteed 1 Secretary with its 36 votes. Therefore, the allocation of the Secretaries would have been more proportional.

To measure the degree of proportionality, the absolute disproportionality index is defined in the next subsection, and the number of seats non proportionally allocated, is calculated.

\subsection{Absolute Disproportionality Index}

The absolute disproportionality index was defined by [11]. It is mostly known as the absolute index. After a brief review of the literature, we can state that it is one of the most widely used indices due to it being easily understood. It is explained as the percentage of seats not allocated proportionally in the vote.

According to [12] this index works as follows:

- For each group $i$, the number of seats allotted after the distribution, which is known as the effective number $(E)$, is calculated. Likewise, the number of seats that each group $i$ would obtain under a pure proportional distribution, which is known as the natural number $(N)$, is calculated.

- The differences in absolute value are added and the result is divided by two. The result is given in terms of percentages:

$$
L H=\frac{1}{2} \sum_{i=1}^{n}\left|E_{i}-N_{i}\right|
$$

In the IX Legislature, with 129 seats divided into 2 groups (PP, UPyD, IU, 93, and PSOE, 36), 7 positions should be allocated. This is a simple example, since there are only two coalitions involved (Table 8). Nevertheless, there are legislatures with more groups, all calculations are available in Appendix A. 
Table 8. Absolute disproportionality index.

\begin{tabular}{cccccc}
\hline $\mathbf{2 0 1 1}$ & $\mathbf{\%}$ & Seats & Effective Number & Natural Number & Differences \\
\hline PP, UPyD y IU & 0.72 & 93 & 6 & 5.05 & 0.95 \\
PSOE & 0.28 & 36 & 1 & 1.95 & -0.95 \\
& Sum & 129 & 7 & 7 & 0 \\
\hline
\end{tabular}

In the table, the coalitions and its proportion seats $(93 / 129 ; 36 / 129)$ are presented. The effective number is the number of Members that each coalition obtained in the election. The natural number is calculated by multiplying the proportion of seats times the number of posts (7). Positive differences show us the coalitions with more seats than proportionally allocated and negative differences show the opposite.

According to the mechanics of the index calculation, there are positive differences (PP, UPyD and IU have 0.95 seats more than those gained proportionally) and negative differences (PSOE has 0.95 seats less than gained proportionally). This is called group excess. The values of the positive (over-represented groups) and the negative (under-represented groups) deviations are equal, so the sum of both cancels out. Another way to obtain the number of seats non-proportionally allocated is merely adding up the positive differences.

For a value of the index $L H=\frac{0.95+0.95}{2}=0.95$, with seven seats, the absolute disproportionality index (in percentage) is (0.95 times 7), i.e., 6.67\%. This number indicates that $6.67 \%$ of the total number of seats have not been distributed proportionally. We can also add up all positive differences to get the precise number of seats that have not been distributed proportionally, i.e., 0.95 seats. This is despite the use of a proportional allocation method.

The basic concepts used in the article have been explained in this section. The next section summarizes the description of the model from the perspective of the game theory and the relationship between the Nash equilibrium of voting and the d'Hondt distribution.

\section{Theoretical Framework}

Pérez, J. and De la Cruz, O [2] proved a relation between the d'Hondt allocation and the Nash equilibrium in the voting method for a situation such as the one analyzed in this work, if certain hypotheses are met.

Assume a House with $n$ Deputies, divided into $k$ parliamentary groups, with sizes $n_{1}, n_{2}, \ldots, n_{k}$, who elect a committee of $q$ equal positions. The sum of the group sizes coincides with the total size of the House. That is, $n_{1}+n_{2}+\ldots+n_{k}=n$. In this game, the parliamentary groups are the players.

Hypothesis 1 (H1). All Members of a group are candidates (so they are of their group), and all Members vote simultaneously.

Hypothesis 2 (H2). Weak version: fractional voting not allowed): Each voter must vote for only one candidate.

Hypothesis 3 (H3). The q candidates with the most votes are elected. Ties are settled randomly.

The first seat will be allocated to the candidate with the most votes. Positions that have already been allocated are excluded and the process continues until all positions have been allocated. Ties are breaking randomly (each tied candidate has the same probability).

Although all voters are Members of the Assembly, it is assumed that full voting discipline is guaranteed according to the following hypothesis:

Hypothesis 4 (H4). In each parliamentary group, a leader decides how each Member of the group will vote. 
In other words, each group $j$ can be considered as a team consisting of $n_{j}$ voters. Therefore, the players of this game are $k$ groups, and the possible action of group $j$ is the distribution of its $n_{j}$ votes among the $n$ candidates.

The $n$ Members of the Assembly are assumed to be loyal and in order. This means that Members of a group always vote for their group. Then, any action $a_{j}$ of group $j$ can be described as an n-vector $\left(a_{j 1}, a_{j 2}, . ., a_{j n}\right)$ with rational and non-negative components such that $\sum_{i=1}^{n} a_{j i}=n_{j}$ and $a_{j i}$ stands for the number of votes that group $j$ gives to the Member (candidate) $i$.

The $n$-vector $\left(v_{1}, v_{2}, \ldots, v_{n}\right)$, with $v_{i}=\sum_{j=1}^{k} a_{j i}$ as the total number of votes obtained by candidate $i$, states the results in votes of the game. Any other information that will not show in the results, such as the name of individual voters, is irrelevant for this analysis.

Given an outcome, it is possible to calculate, applying the hypotheses about the rules of the game, two new results. The first is the $k$-vector $\left(e_{1}, e_{2}, \ldots, e_{k}\right)$ formed by the expected number of seats won by each group. The second is the $k$-vector $\left(r_{1}, r_{2}, \ldots, r_{k}\right)$ formed by the number of positions obtained by each group.

Hypothesis 5 (H5). Given two results, $O$ and $\mathrm{O}^{\prime}$, and the corresponding expected vector of results $\left(e_{1}, e_{2}, \ldots, e_{k}\right)$ and $\left(e^{\prime}{ }_{1}, e^{\prime}{ }_{2}, \ldots, e^{\prime}{ }_{k}\right)$, if $e_{j}>e^{\prime}{ }_{j}$, then group $j$ strictly prefers $O$ to $O^{\prime}$.

In other words, each group strictly prefers more seats than less, regardless of any other element of the voting outcome. Then, the number of seats won is more important than the identity of the elected Members, the identity of the voters of the elected Members, the total number of votes won, the number of seats won by other parties, and so on.

Given a result $\left(v_{1}, v_{2}, \ldots, v_{n}\right)$, we denote $V_{j}$ as the total number of votes obtained by the candidates of group $j$. Then $V_{j}=\sum_{i} v_{i}$, with $i$ as a member of group $j$.

Hypothesis 6 (H6). If the number of seats obtained is the same, each group strictly prefers more votes than less.

This assumption means that, if two results $O=\left(v_{1}, v_{2}, \ldots, v_{n}\right)$ and $O^{\prime}=\left(v^{\prime}{ }_{1}, v^{\prime}{ }_{2}, \ldots\right.$, $v_{n}^{\prime}$ ) lead to the same number of expected seats for group $j$, and the total number of votes obtained in $O$ by the candidates of group $j\left(V_{j}\right)$ is greater than that of $O^{\prime}\left(V^{\prime}{ }_{j}\right)$, then group $j$ strictly prefers $O$ to $O^{\prime}$.

This statement implies that, in the case that a group $j$ could help another group with its spare votes (useless for the number of seats already won and short to gain an additional seat), this group will prefer to vote for its own candidates.

Pérez, J. and De la Cruz, O [2] proved that, for this voting situation, the Jefferson$\mathrm{d}$ 'Hondt allocation is the only allocation method substantiated by a Nash equilibrium.

In the previous sections, the NE and the d'Hondt allocation of Vice-Presidents and Secretaries of the Regional Election of the Assembly of Madrid of 2011 have been analysed separately and the result was the same: Three Vice-Presidents were allocated 2 to PP + IU + UpyD and 1 to PSOE. Three Secretaries were allocated to PP + IU + UpyD and 0 to PSOE.

This theoretical frame is going to be checked with the votes of the legislatures in the Madrid Assembly. This article studies the static game depending on the number of stages, which is explained in the methodology.

\section{Methodology}

This section presents the way in which the analysis has been undertaken in this paper. First, four possibilities for dividing the vote for the seven seats in the Bureau are presented. Second, there is a need to distinguish between coalitions and parties. 


\subsection{The Number of Voting Stages}

With a given number of seats to be distributed (7), four ways of calculating the d'Hondt distribution are proposed, depending on the number of voting stages:

1. All seats are voted in a single ballot, $\mathrm{d}^{\prime} \mathrm{H} 7$.

2. There are two stages: President and all other members, $\mathrm{d}^{\prime} \mathrm{H}(1-6)$.

3. There are three stages: 1 President, 3 Vice-Presidents and 3 Secretaries, $\mathrm{d}^{\prime} \mathrm{H}$ (1-3-3).

4. There are four stages: 1 President, 3 Vice Presidents, 2 Secretaries and 1 Secretary, $d^{\prime} H$ (1-3-2-1). This is the method currently in use in the Assembly of Madrid.

Also, the number of voting stages set and the number of positions to appoint in each one, have an impact on the total number of seats won at the Bureau by each group. Then, it is intuitive to think that the greater the number of stages, the more seats the majority group will win. In fact, if the number of stages is equal to the number of posts, all of them will belong to the majority group.

In addition, there must be a winning parliament group, with an absolute majority of votes, to govern a parliament. That coalition will always win the vote, by definition, when a single position is to be voted. This is the case when voting for President. However, if the number of positions to be voted increases, the winning group may not win them all.

In fact, a parliament with one stage and voting for all seats under a single ballot method may imply that the group with the most votes does not gain more representation in the Bureau than another group. In this case, a tie could happen, and the governance of the House would be at risk.

Therefore, voting in two stages: the President and the other positions on the Bureau could be justified (1-6). Article 55 of the Assembly's Rules of Procedure describes the duties of the President: to ensure the smooth running of parliamentary activity, to guide debates and to maintain order.

The functions of the Vice-Presidents are described in rule 56, distinguishing them from the Secretaries by the possibility of replacing the Presidency in a certain order. This situation leads to voting (1-3-3) in three stages, which also happens in all regional parliaments.

Voting for the third Secretary in an additional ballot (1-3-2-1) includes a disproportionality bias towards the group with the most votes that only occurs in the Madrid Assembly. Also, it is known that the $\mathrm{D}^{\prime}$ Hondt rule is a proportionality rule that mostly favors the majority parties. Moreover, splitting the vote into several stages gets greater representation for the majority parties.

For example, if we assume a vote for 3 Secretaries in 2021, with the 136 seats divided into two groups $(92,44)$, and the group having 92 seats (will be divided in 46, 46), this group will win all three seats by voting separately (two seats in one vote and the third one in a separate ballot). Whereas, if all three seats were voted for at the same time, it would need to have 105 seats (more than three times as many as the second group, with 31 seats). It is easy to check that two groups $(105,31)$ will obtain $(3,0)$ because 105 are divided in 35 , 35 and 35 (so, the group with 31 will not obtain any member). Overall, the result of the vote (considering all stages 1-3-2-1) for a group with 92 seats (with 66.18\%) could, theoretically, manage to get six (President, two Vice presidents, and 3 Secretaries) of those seven seats $(85.71 \%)$ as one Vice-President would go to the group with 44 seats.

\subsection{Data and Coalitions versus Parliament Groups}

Data related to the seats of each parliamentary group and the number of votes that each candidate obtain for President, Vice-Presidents and Secretaries were collected from the web of the Assembly of Madrid [1] in the first meeting of each legislature.

As the vote is anonymous, sometimes a candidate of a parliamentary group is elected and she obtains more votes than her group, therefore, we have investigated where the support comes from. This calculus has been completed by the news media and expert interviews to understand what the coalitions of each legislature have been. Therefore, it is an ex-post analysis. For a game-theoretical approach alliances formation you can see [13]. 
Moreover, ideological orientation is less important in this vote. Therefore, coalitions can be made of different political ideas. In fact, extreme right and extreme left groups have had a coalition in some legislatures (i.e., 2011, IX Legislature, PP is right-wing and IU is left-wing, and both belong to the same coalition). The legitimacy of the decisions that the Bureau will take is bigger if there are coalitions with several groups.

We start assuming that parliament groups are players. Later, we consider coalitions (more than one group) as players that could change the analysis. The first trait of a coalition is that some (or all) of the groups in the block win one more seat (at least) than they would if the coalition did not take place.

However, a problem appears when a group comes close to an absolute majority, so it needs the backing of a smaller group. That small group is likely to gain representation at the Bureau because it is collaborating within a coalition that will win. Conversely, there may be a medium-sized group that does not gain any representation at the Bureau.

Hence, to optimize an allocation voting strategy, there is a need for a separate analysis per coalition and per group. The rationale behind a coalition-based study is a better understanding of the alternatives for the allocation of seats. Nevertheless, each seat still belongs to a given group, so its representation is beyond the coalition.

For this study, we assume the coalitions based on the information published by news media. The reason is that the way of voting is anonymous. Therefore, in the first meeting of the legislature we can read the name of the candidate, the number of votes obtained and the position of the candidate in the election. For example, in 2019 a coalition between $\mathrm{PP}+\mathrm{C}^{\prime} \mathrm{s}+\mathrm{VOX}$ was formed [14]. The contrast between coalition in minority groups and no coalitions in the minority groups could lead to the explanation of the differences in voting Vice-Presidents and Secretaries (Tables 9-11).

Table 9. Apportionment of seats in the XI Legislature.

\begin{tabular}{cccccccc}
\hline Group & $\boldsymbol{P P}$ & $\boldsymbol{V O X}$ & $\boldsymbol{M M}$ & $\boldsymbol{P S O E}$ & $\mathbf{C}^{\prime} \mathbf{s}$ & UP & Total \\
\hline Number of seats & 30 & 12 & 20 & 37 & 26 & 7 & 132 \\
\hline
\end{tabular}

Table 10. Voting of Vice-Presidents in the XI Legislature.

\begin{tabular}{cccccc}
\hline Group & $\boldsymbol{P P}$ & VOX & MAS-Madrid & PSOE & Sum \\
\hline Number of votes & 35 & 33 & 30 & 34 & 132 \\
Vice Presidents (VP) & $1^{\circ} \mathrm{VP}$ & $3^{\circ} \mathrm{VP}$ & & $2^{\circ} \mathrm{VP}$ & \\
\hline
\end{tabular}

Table 11. Voting of Secretaries in the XI Legislature.

\begin{tabular}{cccccc}
\hline Group & $\mathbf{P P}$ & MAS-Madrid & PSOE & C's & Sum \\
\hline Number of votes & 68 & 20 & 44 & & 132 \\
Secretaries (2) & $1^{\circ}$ Secret & & $2^{\circ}$ Secret & & \\
Number of votes & & 57 & & 68 & 125 \\
Secretaries (1) & & & & $3^{\text {o Secret }}$ & 7 blank \\
\hline
\end{tabular}

In the ballot to elect the three Vice-Presidents, the votes received by each candidate were (there are 30 votes given to a candidate of Mas-Madrid (MM) that do not obtain a member):

In the two separate ballots for the election of Secretaries, the votes were distributed as follows (in the election for the last one there were seven votes in blank, so there were 132):

As there are many groups with seats, there are several combinations of coalitions. We have analysed three situations in this legislature: coalition in majority and minority groups, coalition only in the majority groups and no coalition at all. Coalition PP + C's + VOX (68 seats) works in all the stages. In contrast, the coalition of all the minority groups, PSOE + MAS-Madrid + UP (64 seats) has enough for Vice-Presidents and PSOE + MASMadrid (57 seats) for Secretaries. Finally, a situation of no coalition is also calculated. 
Moreover, the existing limitation to four in the number of Members in the Bureau per group (not coalition) under Article 52(6) has not been considered in this paper.

\section{Analysis of the Results}

This section describes the results of all voting in the legislatures of the Assembly of Madrid until 2021, and whether they relate to the occurrence of a Nash equilibrium, the number of seats won by each group, and the disproportionality index according to the number of voting stages.

\subsection{Nash Equilibrium and d'Hondt Distribution by Legislatures}

The relationship between the Nash equilibrium and the $\mathrm{d}^{\prime}$ Hondt distribution is true for the data of all voting in the Assembly of Madrid. Consequently, when voting according to the Nash equilibrium, the d'Hondt distribution is satisfied and, in the votes that do not follow the Nash equilibrium, the d'Hondt distribution is not met.

Also, when analysing the voting in stages, the coalition that aims to govern should win, at least, most of the seats on the Bureau (4 out of 7). Then, if there is a group or coalition with more than $50 \%$ of the seats, the President will be elected on the first ballot. Otherwise, it will win the Presidency on the second ballot. A similar approach applies for the final ballot (to elect a single Secretary) as this group will concentrate all its votes to secure the position.

In the vote for the 2 Secretaries, the same group (with more than 50\%) can secure both, if half of its seats exceed the number of seats of the next political group. Nevertheless, this situation has never occurred in the legislatures of the Assembly of Madrid analysed in this work. Therefore, the two groups with the highest number of seats have won one seat each, repeatedly. Then, a Nash equilibrium occurs, and it coincides with the d'Hondt allocation in all ballots. Therefore, the Secretaries vote is easier to calculate.

However, the most interesting analysis of a Nash Equilibrium and its relation to the $\mathrm{d}^{\prime}$ Hondt distribution can be seen in the voting of the three Vice-Presidents. Moreover, knowing that most voting situations do not follow the Nash equilibrium when it occurs, they do not reach the d'Hondt allocation either. Also, noting that such a situation has an impact on the overall $\mathrm{d}^{\prime}$ Hondt allocation, it varies depending on the number of stages that may occur in the voting and the creation of coalitions between political parties.

According to what has been stated so far, the NE always occurred and the $\mathrm{d}^{\prime} \mathrm{Hondt}$ distribution was also reached in the votes for the President and Secretaries. Table 12 relates the NE, the d'Hondt allocation of the votes of the 3 Vice-Presidents and the overall result. We have considered both situations: parliament groups (no coalitions) and coalitions with more than one parliament group depending on the news media analysed by all the legislatures. These results state "Yes" for the cases in which the vote follows a NE or the $\mathrm{d}^{\prime}$ Hondt distribution in Vice-Presidents. "No" is written for the cases in which the vote does not follow a NE or d'Hondt distribution. In Appendix A, there is a complete analysis.

In the Vice-Presidential voting, a clear relationship between Nash equilibrium and $\mathrm{d}$ 'Hondt allocation was demonstrated. Thus, if the vote is according to the Nash equilibrium, the $\mathrm{d}^{\prime} \mathrm{Hondt}$ allocation is observed for electing the Vice-Presidents and the Bureau distributes the seats following four $\mathrm{d}^{\prime} \mathrm{H}$ stages (1-3-2-1). If voting strategies do not follow Nash equilibrium, the d'Hondt allocation is not satisfied.

Only in 1991, 2011, 2019 and 2021 did the coalitions vote according to a NE. Therefore, the groups' strategies were optimal in those years as they obtained the highest number of seats possible, under the model's assumptions. Considering a coalition as players, the NE and $\mathrm{d}^{\prime}$ Hondt distribution fits better with the theoretical model, than parliament groups.

\subsection{Stages and Agreements}

If we understand that, even if a Nash equilibrium occurred, the voting (based on group strategies) in most Legislatures did not follow the NE, other factors must therefore be considered. Those are the overall allocation of deputies (i.e., the 1995 Legislature) and 
the order in the Vice-Presidential ballot (i.e., 2015). The main reason for the difference between the theoretical analysis and the data comes from the agreements of the coalitions to gain the majority of the Bureau (4 of 7 Members). These agreements lead to a voting outcome that fits with the d'Hondt allocation in one stage or two stages.

Table 12. Nash equilibrium and d'Hondt distribution by legislatures.

\begin{tabular}{|c|c|c|c|c|}
\hline & & E.Nash & D'Hondt Vice-P. & Global d'Hondt \\
\hline \multirow[t]{2}{*}{2021} & With coalitions & Yes & Yes & $\mathrm{d}^{\prime} \mathrm{H}(1-3-2-1)$ \\
\hline & Without coalitions & No & No & No \\
\hline \multirow[t]{2}{*}{2019} & With coalitions & Yes & Yes & $\mathrm{d}^{\prime} \mathrm{H}(1-3-2-1)$ \\
\hline & Without coalitions & No & No & No \\
\hline \multirow[t]{2}{*}{2015} & With coalitions & No & No & $\mathrm{d}^{\prime} \mathrm{H}(1-6)$ or $\mathrm{d}^{\prime} \mathrm{H}(7)$ \\
\hline & Without coalitions & No & No & $\mathrm{d}^{\prime} \mathrm{H}(1-6)$ or $\mathrm{d}^{\prime} \mathrm{H}(7)$ \\
\hline \multirow[t]{2}{*}{2011} & With coalitions & Yes & Yes & $\mathrm{d}^{\prime} \mathrm{H}(1-3-2-1)$ \\
\hline & Without coalitions & No & No & No \\
\hline 2007 & No coalitions & No & No & No \\
\hline $2003 N$ & No coalitions & No & No & No \\
\hline 2003J & No coalitions & No & No & No \\
\hline 1999 & No coalitions & No & No & No \\
\hline 1995 & No coalitions & No & No & $\mathrm{d}^{\prime} \mathrm{H}(1-6)$ or $\mathrm{d}^{\prime} \mathrm{H}(7)$ \\
\hline \multirow[t]{2}{*}{1991} & With coalitions & Yes & Yes & $\mathrm{d}^{\prime} \mathrm{H}(1-3-2-1)$ \\
\hline & Without coalitions & No & No & No \\
\hline \multirow[t]{2}{*}{1987} & With coalitions & No & No & No \\
\hline & Without coalitions & No & No & No \\
\hline 1983 & No coalitions & $\mathrm{No}$ & No & No \\
\hline
\end{tabular}

In the years 1995 and 2015, the results were the same as the ones obtained with a $\mathrm{d}^{\prime}$ Hondt distribution, if all 7 seats were voted simultaneously. Furthermore, if the President was voted for in one ballot and the rest of the seats (6) in a second ballot, it is worth commenting further on the 2015 elections (X Legislature), in Table 13:

Table 13. Relationship between the number of positions obtained and the $\mathrm{d}^{\prime}$ Hondt distributions in the $\mathrm{X}$ Legislature.

\begin{tabular}{ccccccc}
\hline $\mathbf{2 0 1 5}$ & Seats with Coalitions & Vote & $\mathrm{d}^{\prime} \mathbf{H} \mathbf{( 1 - 3 - 2 - 1 )}$ & $\mathrm{d}^{\prime} \mathbf{H}(\mathbf{1 - 3}-\mathbf{3})$ & $\mathrm{d}^{\prime} \mathbf{H}(\mathbf{1 - 6})$ & $\mathrm{d}^{\prime} \mathbf{H} \mathbf{~ ( 7 )}$ \\
\hline PP, C's & 65 & 4 & 5 & 5 & 4 & 4 \\
PSOE & 36 & 2 & 2 & 2 & 2 & 2 \\
Podemos & 27 & 1 & & & 1 & 1 \\
TOTAL & 128 & 7 & 7 & 7 & 7 & 7 \\
\hline
\end{tabular}

PP and C's obtained the President, 1 Vice-Presidents and 2 Secretaries. PSOE got 1 Vice-Presidents and 1 Secretary and Podemos, 1 Vice-President. The vote of the President and the Secretaries satisfies NE and d'Hondt. In the vote for the 3 Vice-Presidents, the Nash equilibrium was not followed because each group won a seat clustering all the seats $(65,36$ and 27). Instead, the 65 votes of the PP and C's group could have been divided into 33,32 , obtaining 2 seats instead of only one. In this way, the first Vice-President would have been for PSOE, with 36, and the other 2 Vice-Presidents would have been for the PP and C's coalition.

This situation raises the question: why is a Nash equilibrium not followed when it occurs? In the above example, the answer is probably linked to the significance of the first Vice-President. Therefore, the model did not take into consideration the sequence as a factor, because rational thinking states that, underpinning the number of seats is 
more important than the order. However, if a group is guaranteed a majority (four out of seven seats), then order could become a relevant factor.

In our model groups, they always prefer more seats than less but, in some legislatures, the result is that groups obtaining four do not care about getting more. In these cases, NE and (1-3-2-1) d'Hondt allocation is not followed. The result is more proportionality because groups with a small number of seats obtain members in the bureau.

In the legislatures where NE is not followed and nor is d'Hondt allocation found, all the members of each group cluster their votes to their candidate, instead of dividing to obtain more posts. Therefore, there is an agreement before voting, as news and media write.

\subsection{Results Related with the Disproportionality Index}

We can further analyse the $\mathrm{X}$ legislature in Table 14, by calculating the excess outcome of each group over the proportional result (number of seats obtained over total). The PP and C's coalition, with 65 seats out of 128 (51\%), has a natural number equal to $0.51 * 7$ Members $=3.57$ and an effective number of 4 (result in the vote), so the excess outcome for the coalition is $4-3.57=0.45$, so the coalition has 0.45 Members more than proportional. PSOE, with 36 seats $(0.28)$, has an excess outcome of $2-7 * 0.28=0.03$ (decimals counted). Both are over-represented, while Podemos, with 27 seats $(0.21)$, is under-represented $(1-7 * 0.21=-0.48)$.

Table 14. Excess per group-absolute Indices of disproportionality, according to the d'Hondt distributions and the number of seats non-proportionally allocated in the $\mathrm{X}$ Legislature.

\begin{tabular}{ccccccc}
\hline \multirow{2}{*}{$\mathbf{2 0 1 5}$} & $\mathbf{\%}$ & Vote & $\mathbf{d}^{\prime} \mathbf{H} \mathbf{( 1 - 3 - 2 - 1 )}$ & $\mathbf{d}^{\prime} \mathbf{H} \mathbf{( 1 - 3 - 3 )}$ & $\mathbf{d}^{\prime} \mathbf{H}$ (1-6) & $\mathbf{d}^{\prime} \mathbf{H} \mathbf{~ ( 7 ) ~}$ \\
\hline PP, C's & 51 & 0.45 & 1.45 & 1.45 & 0.45 & 0.45 \\
PSOE & 28 & 0.03 & 0.03 & 0.03 & 0.03 & 0.03 \\
Podemos & 21 & -0.48 & -1.48 & -1.48 & -0.48 & -0.48 \\
& LH \% & 3.34 & 10.34 & 10.34 & 3.34 & 3.34 \\
& N $^{\circ}$ LH & 0.48 & 1.48 & 1.48 & 0.48 & 0.48 \\
\hline
\end{tabular}

Also, the absolute disproportionality index is available, which is the lowest possible value of anyone drawn for all possible stages. The result follows the d'Hondt distribution if all were to vote at the same time or, if the President were to vote first and then the rest. This outcome could signal a comprehensive agreement for the Bureau to get the lowest disproportionality level (3.34\%) as opposed to the $10.34 \%$ attained if voting with $\mathrm{d}^{\prime}$ Hondt in all four stages (1-3-2-1) or in three stages (1-3-3). In summary, 0.48 seats are not proportionally allocated, compared to 1.48 otherwise.

Moreover, the same result stands for PP and C's when not in a coalition, as shown in Appendix A. Therefore, the result of the 2015 vote is not a Nash equilibrium, the $\mathrm{d}^{\prime}$ Hondt distribution conforms with d'H 7 (and d ' $\mathrm{H}$ (1-6)), and the number of nonproportionally allocated seats would be 0.48 . Then, the interest in calculating the absolute disproportionality index is reinforced by the fact that this situation does not follow the Nash equilibrium and differs from the d'Hondt distribution. Table 15 displays the index as a percentage of the actual vote and the d'Hondt allocations for a given number of stages. For each Legislature, the first row shows the actual voting results with coalitions (in 2019, Vice-Presidents and Secretaries coalitions were different, VP. Coalition: PP, Ciudadanos and VOX coalition versus PSOE, MM and UP coalition and Secret. Coalition: PP, Ciudadanos and VOX coalition versus PSOE, Más-Madrid coalition). The second row presents the mock results without coalitions. 
Table 15. The absolute disproportionality index as a function of d'Hondt distributions.

\begin{tabular}{|c|c|c|c|c|c|c|}
\hline Legislature & Situation & Vote & $d^{\prime} H(1-3-2-1)$ & $\begin{array}{c}\text { LH\% } \\
\text { d'H }^{\prime}(1-3-3)\end{array}$ & $d^{\prime} H(1-6)$ & $d^{\prime} H_{q} q=7$ \\
\hline \multirow[t]{2}{*}{2021} & With coalitions & 6.90 & 6.90 & 6.90 & 0.10 & 0.10 \\
\hline & Without coalitions & 6.90 & 18.58 & 11.58 & 11.58 & 11.58 \\
\hline \multirow[t]{3}{*}{2019} & VP. Coalitions & 9.76 & 9.76 & 9.76 & 2.76 & 2.76 \\
\hline & Secret. Coalitions & 10.02 & 10.02 & 10.02 & 3.02 & 3.02 \\
\hline & Without coalitions & 12.67 & 17.13 & 14.48 & 10.13 & 7.48 \\
\hline \multirow[t]{2}{*}{2015} & With coalitions & 3.34 & 10.34 & 10.34 & 3.34 & 3.34 \\
\hline & Without coalitions & 3.34 & 9.84 & 6.51 & 6.51 & 3.34 \\
\hline \multirow[t]{2}{*}{2011} & With coalitions & 6.67 & 6.67 & 0.33 & 7.33 & 7.33 \\
\hline & Without coalitions & 6.67 & 21.65 & 21.65 & 21.65 & 21.65 \\
\hline 2007 & No coalitions & 3.15 & 7.64 & 7.64 & 7.64 & 4.49 \\
\hline $2003 N$ & No coalitions & 5.86 & 9.84 & 9.84 & 3.97 & 3.97 \\
\hline 2003J & No coalitions & 6.75 & 10.72 & 10.72 & 3.97 & 3.97 \\
\hline 1999 & No coalitions & 4.74 & 8.58 & 8.58 & 3.84 & 3.84 \\
\hline 1995 & No coalitions & 4.74 & 8.58 & 8.58 & 4.74 & 4.74 \\
\hline \multirow[t]{2}{*}{1991} & With coalitions & 8.80 & 8.80 & 8.80 & 2.91 & 2.91 \\
\hline & Without coalitions & 5.89 & 12.20 & 12.20 & 6.31 & 1.80 \\
\hline \multirow[t]{2}{*}{1987} & With coalitions & 4.01 & 19.91 & 19.91 & 7.58 & 5.25 \\
\hline & Without coalitions & 3.43 & 5.91 & 5.91 & 5.91 & 4.67 \\
\hline \multirow[t]{3}{*}{1983} & No coalitions & 3.58 & 7.84 & 7.84 & 4.26 & 4.26 \\
\hline & Average & 6.17 & 11.10 & 10.08 & 6.19 & 5.29 \\
\hline & Standard deviation & 2.59 & 4.55 & 4.64 & 4.52 & 4.52 \\
\hline
\end{tabular}

The table shows that the lowest value of the index was $3.15 \%$ in 2007 , and the highest value was close to $10 \%$ in 2019 (alternative coalitions were possible). Furthermore, if the number of stages increased, the percentage of disproportionality was higher. It is also worth noting that, except for the years in which the Nash equilibrium applied, the disproportionality values were lower than those that would have been achieved if the Nash equilibrium had been followed in the $\mathrm{d}^{\prime}$ Hondt distribution (1-3-2-1).

In fact, the average of the absolute index of disproportionality in the actual vote $(6.17 \%)$ of all legislatures is between the average of the $\mathrm{d}^{\prime}$ Hondt distribution when voting for all seats in one stage ( $\left.\mathrm{d}^{\prime} \mathrm{H} 7\right), 5.29 \%$, and that of the $\mathrm{d}^{\prime}$ Hondt distribution in two stages (1 President and the rest, d'H 1-6), 6.19\%. These results support the conclusion that, following NE and (1-3-2-1) d'Hondt allocation, will yield more disproportionality votes.

\subsection{Results of the Number of Posts Non-Proportionally Allocated}

For a more intuitive interpretation of this absolute disproportionality index, Table 16 displays the number of non-proportionally allocated seats, out of 7 (No. LH), according to the number of stages. Throughout the legislatures, a comparative analysis of the voting results shows an upward trend in the number of stages, except for 2015.

It is worth noting, to assess voting methods, that the number of seats non-proportionally allocated from the actual seat allocation, is less than the one obtained with the four $\mathrm{d}^{\prime} \mathrm{Hondt}$ stages (1-3-2-1) in six of 19 situations analysed. In other words, $32 \%$ of the time the agreements and coalitions reduced the disproportionality of a d'Hondt allocation (1-3-2-1) by not following a Nash equilibrium. 
Table 16. Number of posts non-proportionally allocated as a function of d'Hondt distributions.

\begin{tabular}{|c|c|c|c|c|c|c|}
\hline Legislature & Situation & Vote & $d^{\prime} H(1-3-2-1)$ & $\begin{array}{r}N^{\circ} L H \\
d^{\prime} H(1-3-3)\end{array}$ & $d^{\prime} H(1-6)$ & $d^{\prime} H(7)$ \\
\hline \multirow[t]{2}{*}{2021} & With coalitions & 0.99 & 0.99 & 0.99 & 0.01 & 0.01 \\
\hline & Without coalitions & 0.99 & 2.65 & 1.65 & 1.65 & 1.65 \\
\hline \multirow[t]{3}{*}{2019} & VP. coalitions & 1.39 & 1.39 & 1.39 & 0.39 & 0.39 \\
\hline & Secret. coalitions & 1.43 & 1.43 & 1.43 & 0.43 & 0.43 \\
\hline & Without coalitions & 1.81 & 2.45 & 2.07 & 1.45 & 1.07 \\
\hline \multirow[t]{2}{*}{2015} & With coalitions & 0.48 & 1.48 & 1.48 & 0.48 & 0.48 \\
\hline & Without coalitions & 0.48 & 1.41 & 0.93 & 0.93 & 0.48 \\
\hline \multirow[t]{2}{*}{2011} & With coalitions & 0.95 & 0.95 & 0.05 & 1.05 & 1.05 \\
\hline & Without coalitions & 0.95 & 3.09 & 3.09 & 3.09 & 3.09 \\
\hline 2007 & No coalitions & 0.45 & 1.09 & 1.09 & 1.09 & 0.64 \\
\hline $2003 N$ & No coalitions & 0.84 & 1.41 & 1.41 & 0.57 & 0.57 \\
\hline $2003 \mathrm{~J}$ & No coalitions & 0.96 & 1.53 & 1.53 & 0.57 & 0.57 \\
\hline 1999 & No coalitions & 0.68 & 1.23 & 1.23 & 0.55 & 0.55 \\
\hline 1995 & No coalitions & 0.68 & 1.23 & 1.23 & 0.68 & 0.68 \\
\hline \multirow[t]{2}{*}{1991} & With coalitions & 1.26 & 1.26 & 1.26 & 0.42 & 0.42 \\
\hline & Without coalitions & 0.84 & 1.74 & 1.74 & 0.90 & 0.26 \\
\hline \multirow[t]{2}{*}{1987} & With coalitions & 0.57 & 2.84 & 2.84 & 1.08 & 0.75 \\
\hline & Without coalitions & 0.49 & 0.84 & 0.84 & 0.84 & 0.67 \\
\hline \multirow[t]{3}{*}{1983} & No coalitions & 0.51 & 1.12 & 1.12 & 0.61 & 0.61 \\
\hline & Average & 0.88 & 1.59 & 1.44 & 0.88 & 0.76 \\
\hline & ard deviation & 0.37 & 0.65 & 0.66 & 0.65 & 0.65 \\
\hline
\end{tabular}

In fact, given the actual vote data, d'Hondt (1-3-2-1) and (1-3-3) allocations would obtain the same result in $15(79 \%)$ of the total number of situations analysed (with and without coalitions). Only in five situations did the actual vote coincide with a d'Hondt (1-3-2-1) distribution and in four situations with a d'Hondt (1-3-3). Therefore, there is only one case (2011) of a different voting to appoint 3 Secretaries, simultaneously and separately on two different ballots.

In the IX Legislature (2011), the result is a NE. As we have explained in Section 3, PP, UpyD and IU vs. PSOE, with $(93,36)$ seats, obtain $(6,1)$ in four stages d'Hondt $(1-3-2-1)$ vote. Whereas, if they vote following a distribution in three stages (1-3-3), they will obtain $(5,2)$. The number of seats non-proportionally allocated by a d'Hondt distribution in four stages (1-3-2-1) is 0.95, while under (1-3-3) it will be 0.05 .

The mean and standard deviation calculations of the staggered non-proportionally allocated seats illustrate the existing progression along the number of stages. The more stages there are in the voting, the less proportionality that exists. Then, voting for all seven seats in one stage, with an outcome of 0.76 non-proportionally allocated seats, is the most proportional result. Subsequently, voting (1-6) in two stages is 0.88 , voting (1-3-3) in three stages is 1.44 and voting (1-3-2-1) in four stages is 1.59 non-proportional allocated seats. The actual mean of the voting in all the legislatures is 0.88 (which is in between voting for all seven seats in one ballot and voting in two stages) weighting for the President (the same result as the absolute index of disproportionality). In addition, the standard deviation of the actual voting is lower than that of other voting scenarios, showing more homogeneity of the data (although data with or without coalitions are considered). 


\section{Conclusions}

This work compares the actual result of voting to appoint the Bureau of the Assembly of Madrid with the mock result drawn from the Nash equilibrium (NE) and the d'Hondt $\left(d^{\prime} \mathrm{H}\right)$ allocations in each vote in all the legislatures since its inception (1983-2021). To this end, existing voting stages and the role of coalition-building strategies and the groups' own interests are considered. Also, the over-representation, the absolute disproportionality index, and the number of seats non-proportionally allocated are observed.

The results show that, for the votes in the Assembly of Madrid, the relationship between the Nash equilibrium and a d'Hondt distribution is fulfilled in all legislatures (whether with or without coalitions). Nevertheless, only in four of the situations analysed, (19) were Vice-Presidents elected following a Nash equilibrium (and all the cases in the Secretaries) and the d'Hondt distribution of four stages (1-3-2-1). This happened in the legislatures of 1991, 2011, 2019 and 2021 (all of them with coalitions), showing the highest disproportionality index.

Comparing d'Hondt (1-3-2-1) with (1-3-3), a disproportionality bias has been calculated. Only in the IX Legislature (2011) was the result different. The vote was a NE and matched the (1-3-2-1) d'Hondt allocation with a disproportionality index of $6.67 \%$. However, if it was voted in (1-3-3), the disproportionality index would be $0.33 \%$. In 2015 , without coalitions, there would also have been a difference of $9.84 \%$ in (1-3-2-1), vs. $6.51 \%$ in (1-3-3). This is 1.41 seats non proportionality allocated vs. 0.93 .

In three other situations the Nash Equilibrium was not followed, but the distribution coincided with the d'Hondt allocations of (1-6) or 7, in 2015 (with and without coalitions) and in 1995. In the remaining 12 situations, the votes did not follow a Nash equilibrium nor a d'Hondt distribution.

The reasons behind this are twofold: the significant role of the sequence in the voting of seats once a group reaches four seats (i.e., the majority of the Bureau), and the act of giving seats to groups that would be left without representation in 1983, 1987, 1991 (without coalitions), 1995, 1999, June and November 2003, 2007, 2011 (without coalitions) and 2021 (without coalitions). Either way, groups have their own incentives to move towards Nash equilibrium and, thus, to renege on the pacts.

Moreover, the assumption that majority groups (a win of four out of seven seats) are eager to achieve additional goals, i.e., a better order in the Vice-Presidential voting, is met in all legislatures. When a coalition has an absolute majority and gains four out of seven, it could have an interest in leaving three posts to minority groups because the decisions of the parliament will have more legitimacy.

Additionally, the absolute index of disproportionality and the number of non-proportionally allocated seats perform in the same way based on the number of voting stages: the higher the number of stages, the lower the proportionality that occurs. For the series of votes reviewed, on average, an absolute index of disproportionality was located between the $d^{\prime}$ Hondt allocation of voting all seats in one stage, and the distribution of voting in two stages. Moreover, in six of the 19 situations analysed, the number of the actual seats non-proportionally allocated was lower than that obtained with the four $\mathrm{d}^{\prime} \mathrm{H}$ stages (1-3-2-1).

Moreover, media reports show that coalition building is preferred when an overall agreement cannot be reached. This is because the $\mathrm{D}^{\prime}$ Hondt method, with several stages in the voting, favors the majority groups by preventing minority groups from getting the President and the majority of the Bureau. D'Hondt gives stability $[15,16]$.

In summary, the above results are consistent with academic theory: when voting according to the NE, the d'H distribution (1-3-2-1) and the highest degree of disproportionality are reached. Mostly, parliamentary groups agree on avoiding the NE in voting to gain more proportionality. This is because they do not need to win all the seats on the Bureau to govern as it is enough to have four of the seven seats to secure a ruling.

Ultimately, many of the votes to elect the Members of the Bureau seem to have been agreed beforehand, but this assumption should not always be true. Moreover, there could 
be potential incentives for a group not to abide by the agreements in staged votes such as to win an additional position by splitting the seats in the voting.

A future research opportunity in this work would be to model the preferences of all parliamentary groups to reinforce their voting position as a dynamic game. This approach would allow for the construction of a sub-game perfect Nash equilibrium. If players follow one NE in the last stage, then, by backward induction, there will be an NE in the earlier stage, and so on. A formal proof is needed.

Author Contributions: Conceptualization, F.T.B. and O.d.l.C.V.; methodology, O.d.l.C.V.; software, O.d.l.C.V.; validation, O.d.l.C.V., F.T.B. and R.R.M.; formal analysis, O.d.l.C.V.; investigation, R.R.M.; resources, O.d.l.C.V.; data curation, O.d.l.C.V.; writing-original draft preparation, R.R.M.; writingreview and editing, R.R.M. and O.d.l.C.V.; visualization, F.T.B.; supervision, R.R; project administration, F.T.B. All authors have read and agreed to the published version of the manuscript.

Funding: This research received no external funding.

Institutional Review Board Statement: Not applicable.

Informed Consent Statement: Not applicable.

Data Availability Statement: Reglamento de la Asamblea-Asamblea de Madrid. Asamblea de Madrid. 2019. Available online: https:/ / www.asambleamadrid.es/servicios/normativa/reglamentoasamblea (accessed on 26 September 2021).

Conflicts of Interest: The authors declare no conflict of interest.

\section{Appendix A. Number of Posts and the Disproportionality Index According to the Number of Stages}

In the tables below, the reading is as follows:

Two situations are proposed for each Legislature, one with coalitions and another one without them. For every legislature, only one case exists by situation except in 2019, when two alternative situations of coalitions were considered.

The columns display data about the number of seats won by the group, the result of the positions obtained, and the $\mathrm{d}^{\prime}$ Hondt allocation according to the number of stages as explained in the methodology. Then, the power of each group was calculated in $\%$ as the number of seats out of the total. Also, excess per group/party was defined as the number of seats won by each party (the effective number) minus the natural number (i.e., the power ratio $\%$ multiplied by 7 , the total number of seats). Finally, the disproportionality index $(\mathrm{LH} \%)$ as the percentage of seats and the precise number (No LH) of non-proportionally allocated seats.

Examples of the legislatures that started in 2015 and 2019 were shown in the section on the analysis of the results. They illustrate the information displayed below.

Table A1. Number of posts and the Disproportionality Index according to the number of states.

\begin{tabular}{|c|c|c|c|c|c|c|}
\hline 2021 & Seats with Coalitions & Vote & $d^{\prime} H(1-3-2-1)$ & $\mathrm{d}^{\prime} \mathbf{H}(1-3-3)$ & $d^{\prime} H(1-6)$ & $\mathrm{d}^{\prime} \mathrm{H} \mathrm{q}=7$ \\
\hline PP and VOX & 78 & 5 & 5 & 5 & 4 & 4 \\
\hline PSOE, Más-Madrid and UP & 58 & 2 & 2 & 2 & 3 & 3 \\
\hline \multirow[t]{2}{*}{ Sum } & 136 & 7 & 7 & 7 & 7 & 7 \\
\hline & & \multicolumn{5}{|c|}{ Group excess } \\
\hline 2021 & $\%$ & Vote & $\mathrm{d}^{\prime} \mathrm{H}(1-3-2-1)$ & $\mathrm{d}^{\prime} \mathrm{H}(1-3-3)$ & $\mathrm{d}^{\prime} \mathrm{H}(1-6)$ & $\mathrm{d}^{\prime} \mathrm{H} \mathrm{q}=7$ \\
\hline PP and VOX & 0.57 & 0.99 & 0.99 & 0.99 & -0.01 & -0.01 \\
\hline \multirow[t]{3}{*}{ PSOE, Más-Madrid and UP } & 0.43 & -0.99 & -0.99 & -0.99 & 0.01 & 0.01 \\
\hline & LH \% & 6.90 & 6.90 & 6.90 & 0.10 & 0.10 \\
\hline & $\mathrm{N}^{\mathrm{o}} \mathrm{LH}$ & 0.99 & 0.99 & 0.99 & 0.01 & 0.01 \\
\hline
\end{tabular}


Table A1. Cont.

\begin{tabular}{|c|c|c|c|c|c|c|}
\hline 2021 & Seats with Coalitions & Vote & $\mathrm{d}^{\prime} \mathrm{H}(1-3-2-1)$ & $d^{\prime} H(1-3-3)$ & $d^{\prime} H(1-6)$ & $d^{\prime} H_{q}=7$ \\
\hline 2021 & Seats without Coalitions & Vote & $\mathrm{d}^{\prime} \mathrm{H}(1-3-2-1)$ & $\mathrm{d}^{\prime} \mathrm{H}(1-3-3)$ & $\mathrm{d}^{\prime} \mathrm{H}(1-6)$ & $\mathrm{d}^{\prime} \mathrm{H} \mathrm{q}=7$ \\
\hline PP & 65 & 4 & 6 & 5 & 5 & 5 \\
\hline VOX & 13 & 1 & & & & \\
\hline PSOE & 24 & 1 & 0.5 & 1 & 1 & 1 \\
\hline MM & 24 & 1 & 0.5 & 1 & 1 & 1 \\
\hline UP & 10 & & & & & \\
\hline \multirow[t]{2}{*}{ Sum } & 136 & 7 & 7 & 7 & 7 & 7 \\
\hline & & \multicolumn{5}{|c|}{ Group Excess } \\
\hline 2021 & $\%$ & Vote & $\mathrm{d}^{\prime} \mathrm{H}(1-3-2-1)$ & $\mathrm{d}^{\prime} \mathrm{H}(1-3-3)$ & $\mathrm{d}^{\prime} \mathrm{H}(1-6)$ & $\mathrm{d}^{\prime} \mathrm{H} \mathrm{q}=7$ \\
\hline PP & 0.48 & 0.65 & 2.65 & 1.65 & 1.65 & 1.65 \\
\hline VOX & 0.10 & 0.33 & -0.67 & -0.67 & -0.67 & -0.67 \\
\hline PSOE & 0.18 & -0.24 & -0.74 & -0.24 & -0.24 & -0.24 \\
\hline MM & 0.18 & -0.24 & -0.74 & -0.24 & -0.24 & -0.24 \\
\hline \multirow[t]{3}{*}{$\mathrm{UP}$} & 0.07 & -0.51 & -0.51 & -0.51 & -0.51 & -0.51 \\
\hline & $\mathrm{LH} \%$ & 6.90 & 18.58 & 11.58 & 11.58 & 11.58 \\
\hline & $\mathrm{N}^{\mathrm{o}} \mathrm{LH}$ & 0.99 & 2.65 & 1.65 & 1.65 & 1.65 \\
\hline 2019 & Seats with Coalitions & Vote & $\mathrm{d}^{\prime} \mathrm{H}(1-3-2-1)$ & $\mathrm{d}^{\prime} \mathrm{H}(1-3-3)$ & $\mathrm{d}^{\prime} \mathrm{H}(1-6)$ & $\mathrm{d}^{\prime} \mathrm{H}(7)$ \\
\hline $\mathrm{PP}, \mathrm{C}^{\prime} \mathrm{s}$ and VOX & 68 & 5 & 5 & 5 & 4 & 4 \\
\hline PSOE, Más-Madrid and UP & 64 & 2 & 2 & 2 & 3 & 3 \\
\hline \multirow[t]{2}{*}{ Sum } & 132 & 7 & 7 & 7 & 7 & 7 \\
\hline & & \multicolumn{5}{|c|}{ Group Excess } \\
\hline 2019 & $\%$ & Vote & $\mathrm{d}^{\prime} \mathrm{H}(1-3-2-1)$ & $\mathrm{d}^{\prime} \mathrm{H}(1-3-3)$ & $\mathrm{d}^{\prime} \mathrm{H}(1-6)$ & $\mathrm{d}^{\prime} \mathrm{H}(7)$ \\
\hline PP, C's and VOX & 52 & 1.39 & 1.39 & 1.39 & 0.39 & 0.39 \\
\hline \multirow[t]{3}{*}{ PSOE, Más-Madrid and UP } & 48 & -1.39 & -1.39 & -1.39 & -0.39 & -0.39 \\
\hline & $\mathrm{LH} \%$ & 9.76 & 9.76 & 9.76 & 2.76 & 2.76 \\
\hline & $\mathrm{N}^{\circ} \mathrm{LH}$ & 1.39 & 1.39 & 1.39 & 0.39 & 0.39 \\
\hline 2019 & Seats with Coalitions & Vote & $\mathrm{d}^{\prime} \mathrm{H}(1-3-2-1)$ & $\mathrm{d}^{\prime} \mathrm{H}(1-3-3)$ & $\mathrm{d}^{\prime} \mathrm{H}(1-6)$ & $\mathrm{d}^{\prime} \mathrm{H}(7)$ \\
\hline $\mathrm{PP}, \mathrm{C}^{\prime} \mathrm{s}$ and VOX & 68 & 5 & 5 & 5 & 4 & 4 \\
\hline PSOE & 37 & 2 & 2 & 2 & 2 & 2 \\
\hline $\mathrm{MM}$ & 20 & & & & 1 & 1 \\
\hline UP & 7 & & & & & \\
\hline \multirow[t]{2}{*}{ Sum } & 132 & 7 & 7 & 7 & 7 & 7 \\
\hline & & \multicolumn{5}{|c|}{ Group Excess } \\
\hline 2019 & $\%$ & Vote & $\mathrm{d}^{\prime} \mathrm{H}(1-3-2-1)$ & $\mathrm{d}^{\prime} \mathrm{H}(1-3-3)$ & $\mathrm{d}^{\prime} \mathrm{H}(1-6)$ & $\mathrm{d}^{\prime} \mathrm{H}(7)$ \\
\hline PP, C's and VOX & 52 & 1.39 & 1.39 & 1.39 & 0.39 & 0.39 \\
\hline PSOE & 28 & 0.04 & 0.04 & 0.04 & 0.04 & 0.04 \\
\hline MM & 15 & -1.06 & -1.06 & -1.06 & -0.06 & -0.06 \\
\hline \multirow[t]{3}{*}{$\mathrm{UP}$} & 5 & -0.37 & -0.37 & -0.37 & -0.37 & -0.37 \\
\hline & LH \% & 10.02 & 10.02 & 10.02 & 3.02 & 3.02 \\
\hline & $\mathrm{N}^{\mathrm{o}} \mathrm{LH}$ & 1.43 & 1.43 & 1.43 & 0.43 & 0.43 \\
\hline
\end{tabular}


Table A1. Cont.

\begin{tabular}{|c|c|c|c|c|c|c|}
\hline 2021 & Seats with Coalitions & Vote & $\mathrm{d}^{\prime} \mathrm{H}(1-3-2-1)$ & $\mathrm{d}^{\prime} \mathrm{H}(1-3-3)$ & $d^{\prime} H(1-6)$ & $\mathrm{d}^{\prime} \mathrm{H} \mathrm{q}=7$ \\
\hline 2019 & Seats without Coalitions & Vote & $\mathrm{d}^{\prime} \mathrm{H}(1-3-2-1)$ & $\mathrm{d}^{\prime} \mathrm{H}(1-3-3)$ & $\mathrm{d}^{\prime} \mathrm{H}(1-6)$ & $\mathrm{d}^{\prime} \mathrm{H}(7)$ \\
\hline PP & 30 & 3 & 2 & 2 & 2 & 2 \\
\hline$C^{\prime} s$ & 12 & 1 & & & & \\
\hline VOX & 26 & 1 & 1 & 2 & 1 & 2 \\
\hline PSOE & 37 & 2 & 4 & 3 & 3 & 2 \\
\hline MM & 20 & & & & 1 & 1 \\
\hline UP & 7 & & & & & \\
\hline \multirow[t]{2}{*}{ Sum } & 132 & 7 & 7 & 7 & 7 & 7 \\
\hline & & \multicolumn{5}{|c|}{ Group Excess } \\
\hline 2019 & $\%$ & Vote & $\mathrm{d}^{\prime} \mathrm{H}(1-3-2-1)$ & $\mathrm{d}^{\prime} \mathrm{H}(1-3-3)$ & $\mathrm{d}^{\prime} \mathrm{H}(1-6)$ & $\mathrm{d}^{\prime} \mathrm{H}(7)$ \\
\hline PP & 23 & 1.41 & 0.41 & 0.41 & 0.41 & 0.41 \\
\hline$C^{\prime} \mathrm{s}$ & 9 & 0.36 & -0.64 & -0.64 & -0.64 & -0.64 \\
\hline VOX & 20 & -0.38 & -0.38 & 0.62 & -0.38 & 0.62 \\
\hline PSOE & 28 & 0.04 & 2.04 & 1.04 & 1.04 & 0.04 \\
\hline MM & 15 & -1.06 & -1.06 & -1.06 & -0.06 & -0.06 \\
\hline \multirow[t]{3}{*}{ UP } & 5 & -0.37 & -0.37 & -0.37 & -0.37 & -0.37 \\
\hline & $\mathrm{LH} \%$ & 12.67 & 17.13 & 14.48 & 10.13 & 7.48 \\
\hline & $\mathrm{N}^{\circ} \mathrm{LH}$ & 1.81 & 2.45 & 2.07 & 1.45 & 1.07 \\
\hline 2015 & Seats with Coalitions & Vote & $\mathrm{d}^{\prime} \mathrm{H}(1-3-2-1)$ & $\mathrm{d}^{\prime} \mathrm{H}(1-3-3)$ & $\mathrm{d}^{\prime} \mathrm{H}(1-6)$ & $\mathrm{d}^{\prime} \mathrm{H}(7)$ \\
\hline $\mathrm{PP}, \mathrm{C}^{\prime} \mathrm{s}$ & 65 & 4 & 5 & 5 & 4 & 4 \\
\hline PSOE & 36 & 2 & 2 & 2 & 2 & 2 \\
\hline Podemos & 27 & 1 & & & 1 & 1 \\
\hline \multirow[t]{2}{*}{ Sum } & 128 & 7 & 7 & 7 & 7 & 7 \\
\hline & & \multicolumn{5}{|c|}{ Group Excess } \\
\hline 2015 & $\%$ & Vote & $\mathrm{d}^{\prime} \mathrm{H}(1-3-2-1)$ & $\mathrm{d}^{\prime} \mathrm{H}(1-3-3)$ & $\mathrm{d}^{\prime} \mathrm{H}(1-6)$ & $\mathrm{d}^{\prime} \mathrm{H}(7)$ \\
\hline $\mathrm{PP}, \mathrm{C}^{\prime} \mathrm{s}$ & 51 & 0.45 & 1.45 & 1.45 & 0.45 & 0.45 \\
\hline PSOE & 28 & 0.03 & 0.03 & 0.03 & 0.03 & 0.03 \\
\hline \multirow[t]{3}{*}{ Podemos } & 21 & -0.48 & -1.48 & -1.48 & -0.48 & -0.48 \\
\hline & LH \% & 3.34 & 10.34 & 10.34 & 3.34 & 3.34 \\
\hline & $\mathrm{N}^{\circ} \mathrm{LH}$ & 0.48 & 1.48 & 1.48 & 0.48 & 0.48 \\
\hline 2015 & Seats without Coalitions & Vote & $\mathrm{d}^{\prime} \mathrm{H}(1-3-2-1)$ & $\mathrm{d}^{\prime} \mathrm{H}(1-3-3)$ & $\mathrm{d}^{\prime} \mathrm{H}(1-6)$ & $\mathrm{d}^{\prime} \mathrm{H}(7)$ \\
\hline PP & 48 & 3 & 4 & 3 & 3 & 3 \\
\hline$C^{\prime} \mathrm{s}$ & 17 & 1 & & & & 1 \\
\hline PSOE & 36 & 2 & 2 & 2 & 2 & 2 \\
\hline Podemos & 27 & 1 & 1 & 2 & 2 & 1 \\
\hline \multirow[t]{2}{*}{ Sum } & 128 & 7 & 7 & 7 & 7 & 7 \\
\hline & \multicolumn{6}{|c|}{ Group Excess } \\
\hline 2015 & $\%$ & Vote & $\mathrm{d}^{\prime} \mathrm{H}(1-3-2-1)$ & $\mathrm{d}^{\prime} \mathrm{H}(1-3-3)$ & $\mathrm{d}^{\prime} \mathrm{H}(1-6)$ & $\mathrm{d}^{\prime} \mathrm{H}(7)$ \\
\hline $\mathrm{PP}$ & 38 & 0.38 & 1.38 & 0.38 & 0.38 & 0.38 \\
\hline$C^{\prime} s$ & 13 & 0.07 & -0.93 & -0.93 & -0.93 & 0.07 \\
\hline PSOE & 28 & 0.03 & 0.03 & 0.03 & 0.03 & 0.03 \\
\hline
\end{tabular}


Table A1. Cont.

\begin{tabular}{|c|c|c|c|c|c|c|}
\hline 2021 & Seats with Coalitions & Vote & $d^{\prime} H(1-3-2-1)$ & $d^{\prime} H(1-3-3)$ & $d^{\prime} H(1-6)$ & $\mathrm{d}^{\prime} \mathrm{H} \mathrm{q}=7$ \\
\hline \multirow[t]{3}{*}{ Podemos } & 21 & -0.48 & -0.48 & 0.52 & 0.52 & -0.48 \\
\hline & LH \% & 3.34 & 9.84 & 6.51 & 6.51 & 3.34 \\
\hline & $\mathrm{N}^{\circ} \mathrm{LH}$ & 0.48 & 1.41 & 0.93 & 0.93 & 0.48 \\
\hline 2011 & Seats with Coalitions & Vote & d'H (1-3-2-1) & $\mathrm{d}^{\prime} \mathrm{H}(1-3-3)$ & $\mathrm{d}^{\prime} \mathrm{H}(1-6)$ & $\mathrm{d}^{\prime} \mathrm{H}(7)$ \\
\hline PP, UPyD and IU & 93 & 6 & 6 & 5 & 4 & 4 \\
\hline PSOE & 36 & 1 & 1 & 2 & 3 & 3 \\
\hline \multirow[t]{2}{*}{ Sum } & 129 & 7 & 7 & 7 & 7 & 7 \\
\hline & & \multicolumn{5}{|c|}{ Group Excess } \\
\hline 2011 & $\%$ & Vote & $\mathrm{d}^{\prime} \mathrm{H}(1-3-2-1)$ & d'H (1-3-3) & $\mathrm{d}^{\prime} \mathrm{H}(1-6)$ & $\mathrm{d}^{\prime} \mathrm{H}(7)$ \\
\hline PP, UPyD and IU & 93 & 0.95 & 0.95 & -0.05 & -1.05 & -1.05 \\
\hline \multirow[t]{3}{*}{ PSOE } & 36 & -0.95 & -0.95 & 0.05 & 1.05 & 1.05 \\
\hline & LH \% & 6.67 & 6.67 & 0.33 & 7.33 & 7.33 \\
\hline & $\mathrm{N}^{\mathrm{o}} \mathrm{LH}$ & 0.95 & 0.95 & 0.05 & 1.05 & 1.05 \\
\hline 2011 & Seats without Coalitions & Vote & $\mathrm{d}^{\prime} \mathrm{H}(1-3-2-1)$ & $\mathrm{d}^{\prime} \mathrm{H}(1-3-3)$ & $\mathrm{d}^{\prime} \mathrm{H}(1-6)$ & $\mathrm{d}^{\prime} \mathrm{H}(7)$ \\
\hline $\mathrm{PP}$ & 72 & 4 & 7 & 7 & 7 & 7 \\
\hline UPyD & 8 & 1 & & & & \\
\hline IU & 13 & 1 & & & & \\
\hline PSOE & 36 & 1 & & & & \\
\hline \multirow[t]{2}{*}{ Sum } & 129 & 7 & 7 & 7 & 7 & 7 \\
\hline & & \multicolumn{5}{|c|}{ Group Excess } \\
\hline 2011 & $\%$ & Vote & $\mathrm{d}^{\prime} \mathrm{H}(1-3-2-1)$ & $\mathrm{d}^{\prime} \mathrm{H}(1-3-3)$ & $\mathrm{d}^{\prime} \mathrm{H}(1-6)$ & $\mathrm{d}^{\prime} \mathrm{H}(7)$ \\
\hline PP & 56 & 0.09 & 3.09 & 3.09 & 3.09 & 3.09 \\
\hline UPyD & 6 & 0.57 & -0.43 & -0.43 & -0.43 & -0.43 \\
\hline IU & 10 & 0.29 & -0.71 & -0.71 & -0.71 & -0.71 \\
\hline \multirow[t]{3}{*}{ PSOE } & 28 & -0.95 & -1.95 & -1.95 & -1.95 & -1.95 \\
\hline & $\mathrm{LH} \%$ & 6.67 & 21.65 & 21.65 & 21.65 & 21.65 \\
\hline & $\mathrm{N}^{\mathrm{o}} \mathrm{LH}$ & 0.95 & 3.09 & 3.09 & 3.09 & 3.09 \\
\hline 2007 & Seats & Vote & $\mathrm{d}^{\prime} \mathrm{H}(1-3-2-1)$ & $\mathrm{d}^{\prime} \mathrm{H}(1-3-3)$ & $\mathrm{d}^{\prime} \mathrm{H}(1-6)$ & $\mathrm{d}^{\prime} \mathrm{H}(7)$ \\
\hline $\mathrm{PP}$ & 67 & 4 & 5 & 5 & 5 & 4 \\
\hline PSOE & 42 & 2 & 2 & 2 & 2 & 3 \\
\hline IU & 11 & 1 & & & & \\
\hline \multirow[t]{2}{*}{ Sum } & 120 & 7 & 7 & 7 & 7 & 7 \\
\hline & & \multicolumn{5}{|c|}{ Group Excess } \\
\hline 2007 & $\%$ & Vote & $\mathrm{d}^{\prime} \mathrm{H}(1-3-2-1)$ & $\mathrm{d}^{\prime} \mathrm{H}(1-3-3)$ & $\mathrm{d}^{\prime} \mathrm{H}(1-6)$ & $\mathrm{d}^{\prime} \mathrm{H}(7)$ \\
\hline PP & 56 & 0.09 & 1.09 & 1.09 & 1.09 & 0.09 \\
\hline PSOE & 35 & -0.45 & -0.45 & -0.45 & -0.45 & 0.55 \\
\hline \multirow[t]{3}{*}{ IU } & 9 & 0.36 & -0.64 & -0.64 & -0.64 & -0.64 \\
\hline & LH \% & 3.15 & 7.64 & 7.64 & 7.64 & 4.49 \\
\hline & $\mathrm{N}^{\circ} \mathrm{LH}$ & 0.45 & 1.09 & 1.09 & 1.09 & 0.64 \\
\hline 2003 Nov & & Vote & $\mathrm{d}^{\prime} \mathrm{H}(1-3-2-1)$ & $\mathrm{d}^{\prime} \mathrm{H}(1-3-3)$ & d'H (1-6) & $\mathrm{d}^{\prime} \mathrm{H}(7)$ \\
\hline $\mathrm{PP}$ & 57 & 4 & 5 & 5 & 4 & 4 \\
\hline PSOE & 45 & 2 & 2 & 2 & 3 & 3 \\
\hline IU & 9 & 1 & & & & \\
\hline
\end{tabular}


Table A1. Cont.

\begin{tabular}{|c|c|c|c|c|c|c|}
\hline 2021 & Seats with Coalitions & Vote & $\mathrm{d}^{\prime} \mathrm{H}(1-3-2-1)$ & $\mathrm{d}^{\prime} \mathrm{H}(1-3-3)$ & $d^{\prime} H(1-6)$ & $\mathrm{d}^{\prime} \mathrm{H} \mathrm{q}=7$ \\
\hline Sum & 111 & 7 & 7 & 7 & 7 & 7 \\
\hline & & \multicolumn{5}{|c|}{ Group Excess } \\
\hline 2003 Nov & $\%$ & Vote & $\mathrm{d}^{\prime} \mathrm{H}(1-3-2-1)$ & $\mathrm{d}^{\prime} \mathrm{H}(1-3-3)$ & $\mathrm{d}^{\prime} \mathrm{H}(1-6)$ & $\mathrm{d}^{\prime} \mathrm{H}(7)$ \\
\hline $\mathrm{PP}$ & 51 & 0.41 & 1.41 & 1.41 & 0.41 & 0.41 \\
\hline PSOE & 41 & -0.84 & -0.84 & -0.84 & 0.16 & 0.16 \\
\hline \multirow[t]{3}{*}{ IU } & 8 & 0.43 & -0.57 & -0.57 & -0.57 & -0.57 \\
\hline & LH \% & 5.86 & 9.84 & 9.84 & 3.97 & 3.97 \\
\hline & $\mathrm{N}^{\mathrm{o}} \mathrm{LH}$ & 0.84 & 1.41 & 1.41 & 0.57 & 0.57 \\
\hline 2003 Jun & Seats & Vote & $\mathrm{d}^{\prime} \mathrm{H}(1-3-2-1)$ & $\mathrm{d}^{\prime} \mathrm{H}(1-3-3)$ & $\mathrm{d}^{\prime} \mathrm{H}(1-6)$ & $\mathrm{d}^{\prime} \mathrm{H}(7)$ \\
\hline PP & 55 & 4 & 5 & 5 & 4 & 4 \\
\hline PSOE & 47 & 2 & 2 & 2 & 3 & 3 \\
\hline $\mathrm{IU}$ & 9 & 1 & & & & \\
\hline \multirow[t]{2}{*}{ Sum } & 111 & 7 & 7 & 7 & 7 & 7 \\
\hline & & \multicolumn{5}{|c|}{ Group Excess } \\
\hline 2003 Jun & $\%$ & Vote & $\mathrm{d}^{\prime} \mathrm{H}(1-3-2-1)$ & $\mathrm{d}^{\prime} \mathrm{H}(1-3-3)$ & $\mathrm{d}^{\prime} \mathrm{H}(1-6)$ & $\mathrm{d}^{\prime} \mathrm{H}(7)$ \\
\hline PP & 50 & 0.53 & 1.53 & 1.53 & 0.53 & 0.53 \\
\hline PSOE & 42 & -0.96 & -0.96 & -0.96 & 0.04 & 0.04 \\
\hline \multirow[t]{3}{*}{$\mathrm{IU}$} & 8 & 0.43 & -0.57 & -0.57 & -0.57 & -0.57 \\
\hline & LH \% & 6.75 & 10.72 & 10.72 & 3.97 & 3.97 \\
\hline & $\mathrm{N}^{\circ} \mathrm{LH}$ & 0.96 & 1.53 & 1.53 & 0.57 & 0.57 \\
\hline 1999 & Seats & Vote & $\mathrm{d}^{\prime} \mathrm{H}(1-3-2-1)$ & $\mathrm{d}^{\prime} \mathrm{H}(1-3-3)$ & $\mathrm{d}^{\prime} \mathrm{H}(1-6)$ & $\mathrm{d}^{\prime} \mathrm{H}(7)$ \\
\hline PP & 55 & 4 & 5 & 5 & 4 & 4 \\
\hline PSOE & 39 & 2 & 2 & 2 & 3 & 3 \\
\hline IU & 8 & 1 & & & & \\
\hline \multirow[t]{2}{*}{ Sum } & 102 & 7 & 7 & 7 & 7 & 7 \\
\hline & & \multicolumn{5}{|c|}{ Group Excess } \\
\hline 1999 & $\%$ & Vote & $\mathrm{d}^{\prime} \mathrm{H}(1-3-2-1)$ & $\mathrm{d}^{\prime} \mathrm{H}(1-3-3)$ & $\mathrm{d}^{\prime} \mathrm{H}(1-6)$ & $\mathrm{d}^{\prime} \mathrm{H}(7)$ \\
\hline $\mathrm{PP}$ & 54 & 0.23 & 1.23 & 1.23 & 0.23 & 0.23 \\
\hline PSOE & 38 & -0.68 & -0.68 & -0.68 & 0.32 & 0.32 \\
\hline \multirow[t]{3}{*}{$\mathrm{IU}$} & 8 & 0.45 & -0.55 & -0.55 & -0.55 & -0.55 \\
\hline & LH \% & 4.74 & 8.58 & 8.58 & 3.84 & 3.84 \\
\hline & $\mathrm{N}^{\circ} \mathrm{LH}$ & 0.68 & 1.23 & 1.23 & 0.55 & 0.55 \\
\hline 1995 & Seats with Coalitions & Vote & $\mathrm{d}^{\prime} \mathrm{H}(1-3-2-1)$ & $\mathrm{d}^{\prime} \mathrm{H}(1-3-3)$ & $\mathrm{d}^{\prime} \mathrm{H}(1-6)$ & $\mathrm{d}^{\prime} \mathrm{H}(7)$ \\
\hline PP & 55 & 4 & 5 & 5 & 4 & 4 \\
\hline PSOE & 39 & 2 & 2 & 2 & 2 & 2 \\
\hline IU & 8 & 1 & & & 1 & 1 \\
\hline \multirow[t]{2}{*}{ Sum } & 102 & 7 & 7 & 7 & 7 & 7 \\
\hline & & \multicolumn{5}{|c|}{ Group Excess } \\
\hline 1995 & $\%$ & Vote & $\mathrm{d}^{\prime} \mathrm{H}(1-3-2-1)$ & $\mathrm{d}^{\prime} \mathrm{H}(1-3-3)$ & $\mathrm{d}^{\prime} \mathrm{H}(1-6)$ & $\mathrm{d}^{\prime} \mathrm{H}(7)$ \\
\hline PP & 54 & 0.23 & 1.23 & 1.23 & 0.23 & 0.23 \\
\hline PSOE & 38 & -0.68 & -0.68 & -0.68 & -0.68 & -0.68 \\
\hline IU & 8 & 0.45 & -0.55 & -0.55 & 0.45 & 0.45 \\
\hline
\end{tabular}


Table A1. Cont.

\begin{tabular}{|c|c|c|c|c|c|c|}
\hline 2021 & Seats with Coalitions & Vote & $\mathrm{d}^{\prime} \mathrm{H}(1-3-2-1)$ & $\mathrm{d}^{\prime} \mathrm{H}(1-3-3)$ & $\mathrm{d}^{\prime} \mathrm{H}(1-6)$ & $\mathrm{d}^{\prime} \mathrm{H} \mathrm{q}=7$ \\
\hline & $\mathrm{LH} \%$ & 4.74 & 8.58 & 8.58 & 4.74 & 4.74 \\
\hline & $\mathrm{N}^{\mathrm{o}} \mathrm{LH}$ & 0.68 & 1.23 & 1.23 & 0.68 & 0.68 \\
\hline 1991 & Seats with Coalitions & Vote & $\mathrm{d}^{\prime} \mathrm{H}(1-3-2-1)$ & d'H (1-3-3) & $\mathrm{d}^{\prime} \mathrm{H}(1-6)$ & $\mathrm{d}^{\prime} \mathrm{H}(7)$ \\
\hline PSOE and IU & 54 & 5 & 5 & 5 & 4 & 4 \\
\hline $\mathrm{PP}$ & 41 & 2 & 2 & 2 & 3 & 3 \\
\hline Sum & 101 & 7 & 7 & 7 & 7 & 7 \\
\hline & & \multicolumn{5}{|c|}{ Group Excess } \\
\hline 1991 & $\%$ & Vote & $\mathrm{d}^{\prime} \mathrm{H}(1-3-2-1)$ & $\mathrm{d}^{\prime} \mathrm{H}(1-3-3)$ & $\mathrm{d}^{\prime} \mathrm{H}(1-6)$ & $\mathrm{d}^{\prime} \mathrm{H}(7)$ \\
\hline PSOE and IU & 53 & 1.26 & 1.26 & 1.26 & 0.26 & 0.26 \\
\hline \multirow[t]{3}{*}{$\mathrm{PP}$} & 41 & -0.84 & -0.84 & -0.84 & 0.16 & 0.16 \\
\hline & $\mathrm{LH} \%$ & 8.80 & 8.80 & 8.80 & 2.91 & 2.91 \\
\hline & $\mathrm{N}^{\mathrm{o}} \mathrm{LH}$ & 1.26 & 1.26 & 1.26 & 0.42 & 0.42 \\
\hline 1991 & Seats without Coalitions & Vote & $\mathrm{d}^{\prime} \mathrm{H}(1-3-2-1)$ & $\mathrm{d}^{\prime} \mathrm{H}(1-3-3)$ & $\mathrm{d}^{\prime} \mathrm{H}(1-6)$ & $\mathrm{d}^{\prime} \mathrm{H}(7)$ \\
\hline PSOE & 47 & 4 & 5 & 5 & 4 & 3 \\
\hline PP & 41 & 2 & 2 & 2 & 3 & 3 \\
\hline IU & 13 & 1 & & & & 1 \\
\hline \multirow[t]{2}{*}{ Sum } & 101 & 7 & 7 & 7 & 7 & 7 \\
\hline & & \multicolumn{5}{|c|}{ Group Excess } \\
\hline 1991 & $\%$ & Vote & $\mathrm{d}^{\prime} \mathrm{H}(1-3-2-1)$ & $\mathrm{d}^{\prime} \mathrm{H}(1-3-3)$ & $\mathrm{d}^{\prime} \mathrm{H}(1-6)$ & $\mathrm{d}^{\prime} \mathrm{H}(7)$ \\
\hline PSOE & 47 & 0.74 & 1.74 & 1.74 & 0.74 & -0.26 \\
\hline $\mathrm{PP}$ & 41 & -0.84 & -0.84 & -0.84 & 0.16 & 0.16 \\
\hline \multirow[t]{3}{*}{ IU } & 13 & 0.10 & -0.90 & -0.90 & -0.90 & 0.10 \\
\hline & LH \% & 5.89 & 12.20 & 12.20 & 6.31 & 1.80 \\
\hline & $\mathrm{N}^{\mathrm{o}} \mathrm{LH}$ & 0.84 & 1.74 & 1.74 & 0.90 & 0.26 \\
\hline 1987 & Seats with Coalitions & Vote & $\mathrm{d}^{\prime} \mathrm{H}(1-3-2-1)$ & $\mathrm{d}^{\prime} \mathrm{H}(1-3-3)$ & $\mathrm{d}^{\prime} \mathrm{H}(1-6)$ & $\mathrm{d}^{\prime} \mathrm{H}(7)$ \\
\hline PSOE and CDS & 57 & 4 & 5 & 5 & 5 & 4 \\
\hline FAP & 32 & 2 & 2 & 2 & 2 & 3 \\
\hline IU & 7 & 1 & & & & \\
\hline \multirow[t]{2}{*}{ Sum } & 96 & 7 & 7 & 7 & 7 & 7 \\
\hline & & \multicolumn{5}{|c|}{ Group Excess } \\
\hline 1987 & $\%$ & Vote & $\mathrm{d}^{\prime} \mathrm{H}(1-3-2-1)$ & $\mathrm{d}^{\prime} \mathrm{H}(1-3-3)$ & $\mathrm{d}^{\prime} \mathrm{H}(1-6)$ & $\mathrm{d}^{\prime} \mathrm{H}(7)$ \\
\hline PSOE and CDS & 59 & -0.16 & 0.84 & 0.84 & 0.84 & -0.16 \\
\hline FAP & 33 & -0.33 & -0.33 & -0.33 & -0.33 & 0.67 \\
\hline \multirow[t]{3}{*}{ IU } & 7 & 0.49 & -0.51 & -0.51 & -0.51 & -0.51 \\
\hline & $\mathrm{LH} \%$ & 3.43 & 5.91 & 5.91 & 5.91 & 4.67 \\
\hline & $\mathrm{N}^{\mathrm{o}} \mathrm{LH}$ & 0.49 & 0.84 & 0.84 & 0.84 & 0.67 \\
\hline 1987 & Seats without coalitions & Vote & $\mathrm{d}^{\prime} \mathrm{H}(1-3-2-1)$ & $\mathrm{d}^{\prime} \mathrm{H}(1-3-3)$ & $\mathrm{d}^{\prime} \mathrm{H}(1-6)$ & $\mathrm{d}^{\prime} \mathrm{H}(7)$ \\
\hline PSOE & 40 & 3 & 5 & 5 & 4 & 3 \\
\hline CDS & 17 & 1 & 2 & 2 & 1 & 1 \\
\hline FAP & 32 & 2 & & & 2 & 3 \\
\hline IU & 7 & 1 & & & & \\
\hline Sum & 96 & 7 & 7 & 7 & 7 & 7 \\
\hline
\end{tabular}


Table A1. Cont.

\begin{tabular}{|c|c|c|c|c|c|c|}
\hline 2021 & Seats with Coalitions & Vote & $d^{\prime} H(1-3-2-1)$ & $\mathrm{d}^{\prime} \mathrm{H}(1-3-3)$ & $d^{\prime} H(1-6)$ & $\mathrm{d}^{\prime} \mathrm{H} \mathrm{q}=7$ \\
\hline & & \multicolumn{5}{|c|}{ Group Excess } \\
\hline 1987 & $\%$ & Vote & $\mathrm{d}^{\prime} \mathrm{H}(1-3-2-1)$ & $\mathrm{d}^{\prime} \mathrm{H}(1-3-3)$ & $\mathrm{d}^{\prime} \mathrm{H}(1-6)$ & $\mathrm{d}^{\prime} \mathrm{H}(7)$ \\
\hline PSOE & 42 & 0.08 & 2.08 & 2.08 & 1.08 & 0.08 \\
\hline CDS & 18 & -0.24 & 0.76 & 0.76 & -0.24 & -0.24 \\
\hline FAP & 33 & -0.33 & -2.33 & -2.33 & -0.33 & 0.67 \\
\hline \multirow[t]{3}{*}{ IU } & 7 & 0.49 & -0.51 & -0.51 & -0.51 & -0.51 \\
\hline & LH \% & 4.01 & 19.91 & 19.91 & 7.58 & 5.25 \\
\hline & $\mathrm{N}^{\mathrm{o}} \mathrm{LH}$ & 0.57 & 2.84 & 2.84 & 1.08 & 0.75 \\
\hline 1983 & & Vote & $\mathrm{d}^{\prime} \mathrm{H}(1-2-3-1)$ & $\mathrm{d}^{\prime} \mathrm{H}(1-2-4)$ & $\mathrm{d}^{\prime} \mathrm{H}(1-6)$ & $\mathrm{d}^{\prime} \mathrm{H}(7)$ \\
\hline PSOE & 51 & 4 & 5 & 5 & 4 & 4 \\
\hline FAP & 33 & 2 & 2 & 2 & 3 & 3 \\
\hline PCE & 8 & 1 & & & & \\
\hline \multirow[t]{2}{*}{ Sum } & 92 & 7 & 7 & 7 & 7 & 7 \\
\hline & & \multicolumn{5}{|c|}{ Group Excess } \\
\hline 1983 & $\%$ & Vote & d'H (1-3-2-1) & $\mathrm{d}^{\prime} \mathrm{H}(1-3-3)$ & $\mathrm{d}^{\prime} \mathrm{H}(1-6)$ & $\mathrm{d}^{\prime} \mathrm{H}(7)$ \\
\hline PSOE & 55 & 0.12 & 1.12 & 1.12 & 0.12 & 0.12 \\
\hline FAP & 36 & -0.51 & -0.51 & -0.51 & 0.49 & 0.49 \\
\hline \multirow[t]{3}{*}{ PCE } & 0.09 & 0.39 & -0.61 & -0.61 & -0.61 & -0.61 \\
\hline & LH \% & 3.58 & 7.84 & 7.84 & 4.26 & 4.26 \\
\hline & $\mathrm{N}^{\mathrm{o}} \mathrm{LH}$ & 0.51 & 1.12 & 1.12 & 0.61 & 0.61 \\
\hline
\end{tabular}

\section{Appendix B. Acronyms of Political Groups}

Table A2. Acronyms of Political Groups, legislatures and orientation.

\begin{tabular}{|c|c|c|c|c|}
\hline Acronym & Political Group & In Assembly (\# Legislature) & Ideological Orientation & Remarks \\
\hline CDS & Centro Democrático y Social & II & Liberals & \\
\hline$C^{\prime} s$ & Cuidadanos & $\mathrm{X}, \mathrm{XI}$ & Liberals & \\
\hline FAP & Federación Alianza Popular & I, II & Conservatives & \\
\hline IU & Izquierda Unida & II, III, IV, V, VI, VII, VIII, IX & Hard Left & \\
\hline MM & Mas Madrid & $\mathrm{XII}$ & Hard Left & Former Mas País \\
\hline MP & Mas País & XI & Hard Left & \\
\hline PCE & Partido Comunista Español & $\mathrm{I}$ & Hard Left & \\
\hline PP & Partido Popular & $\begin{array}{c}\text { III, IV, V, VI, VII, VIII, IX, X, } \\
\text { XI, XII }\end{array}$ & Conservatives & Former FAP \\
\hline PSOE & $\begin{array}{l}\text { Partido Socialista Obrero } \\
\text { Español }\end{array}$ & $\begin{array}{c}\text { I, II, III, IV, V, VI, VII, VIII, IX, } \\
\text { X, XI, XII }\end{array}$ & Socialists & \\
\hline Podemos & Podemos & $X, X I$ & Hard Left & \\
\hline UP & Unidas Podemos & XII & Liberals & $\mathrm{IU}+$ Podemos \\
\hline UPyD & $\begin{array}{l}\text { Unión Progreso y } \\
\text { Democracia }\end{array}$ & IX & Liberals & \\
\hline VOX & Vox & $\mathrm{XI}, \mathrm{XII}$ & Hard Right & \\
\hline
\end{tabular}




\section{References}

1. Reglamento de la Asamblea-Asamblea de Madrid. Asamblea de Madrid. 2019. Available online: https://www.asambleamadrid. es/servicios/normativa/reglamento-asamblea (accessed on 25 September 2021).

2. Pérez, J.; De la Cruz, O. Implementation of Jefferson-d'Hondt rule in the formation of a parliamentary committee. Soc. Choice Welf. 2014, 42, 17-30. [CrossRef]

3. Cox, G.W. SNTV and d'Hondt are 'equivalent'. Elect. Stud. 1991, 10, 119-132. [CrossRef]

4. Lijphart, A.; López, R. Alphabetic Bias in Partisan Elections: Patterns of Voting for the Spanish Senate, 1982 and 1986. Elect. Stud. 1988, 7, 225-231. [CrossRef]

5. Lijphart, A.; Pintor, R.L.; Sone, Y. The Limited Vote and the Single Non-Transferable Vote: Lessons from the Japanese and Spanish Examples. In Electoral Laws and Their Political Consequences; Grofman, B., Lijphart, A., Eds.; Agathon Press: New York, NY, USA, 1994; pp. 154-170.

6. Montabes, J.; Ortega, C. Position effects and party nomination strategies under the limited vote: The 2000 Spanish Senate election. Representation 2002, 38, 304-316. [CrossRef]

7. Cerdá, E.; Jimeno, J.L.; Pérez, J. Teoría de Juegos; Pearson Educación: Madrid, Spain, 2004.

8. Shepsle, K. Models of Multiparty Electoral Competition; Routledge: Oxfordshire, UK, 2012.

9. Balinski, M.L.; Young, H.P. Criteria for proportional representation. Oper. Res. 1979, 27, 80-95. [CrossRef]

10. Miller, N.R. Committees, Agendas, and Voting; Harwood Academic Publishers: Amsterdam, The Netherlands, 1995.

11. Vallès, J.M.; Bosch, A. Sistemas Electorales y Gobierno Representativo; Ariel Ciencia Política; Universitat Autònoma de Barcelona: Barcelona, Spain, 1997.

12. Ocaña, F.; Oñate, P. Índices e indicadores del sistema electoral. Una propuesta informática para su cálculo. REIS 1999, 86, 223-245. [CrossRef]

13. Karpov, A. Alliance incentives under the D'Hondt method. Math. Soc. Sci. 2015, 74, 1-7. [CrossRef]

14. Mateo, J.J. PP, Cs y Vox pactan la presidencia de la Asamblea y facilitan el acuerdo para el Ayuntamiento y la Comunidad de Madrid. El País. 2019. Available online: https://elpais.com/ccaa/2019/06/11/madrid/1560236349_187946.html (accessed on 26 September 2021).

15. Cooper, D. The Potential of Cumulative Voting to Yield Fair Representation. J. Theor. Politics 2007, 19, 277-295. [CrossRef]

16. Cox, G.W.; Rosenbluth, F. Reducing Nomination Errors: Factional Competition and Party Strategy in Japan. Elect. Stud. 1994, 13, 4-16. [CrossRef] 